\title{
Revistas Brasileiras em Letras E Lingüística ${ }^{1}$
}

\author{
(Letters and Linguistics Brazilian Journals)
}

Luiz Antônio MARCUsChI (UFPE)

\section{Observações preliminares}

As observações que se seguem a respeito de como deveríamos ou poderíamos nos portar nos próximos anos em relação a periódicos científicos nas áreas de Letras e Lingüística (L\&L), bem como as informações constantes na listagem de revistas anexa formam um subsídio preliminar para reflexão e conferência. Num segundo momento, discussões técnicas, levantamentos mais completos e atualizados deverão confirmar ou rever as propostas e os dados. É possível que algumas revistas arroladas não mais existam e várias outras sequer tenham sido incluídas por simples desconhecimento de minha parte. ${ }^{2} \mathrm{O}$ ideal seria que as áreas de L\&L ainda dispusessem da publicação que já existiu por alguns anos, ou seja, os Sumários Correntes de Periódicos em Letras e Lingüística. ${ }^{3}$ Esse poderia ser um instrumento bastante útil na divulgação da produção científica recente e atualizada. Seu formato poderia ser o de uma informação via Internet para uma atualização permanente, tal como existe em algumas outras áreas.

\footnotetext{
1 Esta comunicação foi apresentada na programação científica da ABRALIN durante a 52a Reunião Anual da SBPC, em Brasília, de 8 a 14 de julho de 2000. O simpósio em que o texto foi apresentado estava a cargo da profa. Leila Barbara (PUC-SP), tendo ainda participado da mesa o prof. Vilson José Leffa (UCPEL). Esta relação foi consideravelmente ampliada a partir daquela comunicação e se encontra aqui com um número grande de periódicos.

2 Algumas revistas estão desativadas, mas a indicação deste dado é difícil e somente uma revisão das informações aqui prestadas pode dar maior precisão a este aspecto. Agradeço à atual presidente da ANPOLL, Profa. Freda Indursky, o apoio na correção destes dados. Uma versão completa desta relação deverá ser divulgada pela ANPOLL no seu portal pela INTERNET.

3 Esta publicação, que chegou ao quinto número sob a orientação do prof. Ulf Gregor Baranow, não teve continuidade. Incluia periódicos nacionais e estrangeiros, estampando apenas o sumário de cada um deles. Só apresentava periódicos que se encontrassem em alguma biblioteca brasileira a fim de que pudessem ser acessados com facilidade.
} 


\section{A Produção Científica e sua Divulgação}

Pode-se perguntar para que servem as revistas científicas, cujas publicações têm hoje mais prestígio que os textos em coletâneas ou até mesmo os próprios manuais. A resposta seria simples: servem como veículo fácil, econômico e rápido para divulgar o conhecimento científico produzido naquele momento. Trata-se de uma estratégia de divulgação imediata, mas que não pode perder de vista a qualidade da produção divulgada. Daí a importância de uma política editorial explícita e um comitê editorial atuante. Em princípio, as revistas deveriam circular com mais agilidade entre os pesquisadores e os estudantes de uma dada área, mas o que se verifica não é bem isto. É surpreendente constatar que nos Cursos de Graduação, a grande maioria dos alunos sequer sabe o nome de alguma revista e poucos as consultam. Parece que a publicação de revistas e seu consumo está ainda restrito à Pós-Graduação.

Que produção merece divulgação? Em princípio, partindo da hipótese de que todo o trabalho científico merece respeito e deve oferecer qualidade, pode-se dizer que toda produção científica merece divulgação. Olhando com atenção as revistas existentes, percebe-se que este não é o caso: há revistas que não são boas. Portanto, aspecto importante, que deverá receber uma definição mais detida tanto por parte dos órgãos de fomento quanto da comunidade, é o que diz respeito ao que se deve considerar como produção científica. ${ }^{4}$ Embora cada área tenha uma percepção do assunto, deve haver algumas regras gerais, sendo necessário, certamente, respeitar critérios específicos de cada área. Todos concordam em que a identificação da produção científica é essencial porque serve como indicador da vitalidade da área.

Ao lado dessas questóes, poderíamos indagar ainda o seguinte: quem publica? No geral, publicam os docentes e pesquisadores da Pós-Graduação, mas já temos revistas de Graduação sendo publicadas. No geral,

\footnotetext{
4 Neste momento não me deterei em todos os aspectos da questão e sim apenas às revistas. Mas será de grande importância abrir um debate sobre o tema abrangendo todo o leque de produção para definir o que entendemos por produção científica em nossas áreas. Por exemplo, em relação a trabalhos em jornais diários, em revistas de divulgação ao grande público e em revistas não especializadas; ou então o caso do valor de livros, capítulos de livros, relatórios técnicos não publicados, mas acessíveis em algum local certo; ou os trabalhos publicados em anais de congressos, resultados de estudos em grupo, divulgação pela Internet e assim por diante.
} 
parece claro que é a Pós-Graduação que oferece hoje o maior contingente de publicaçôes. Contudo, o mapeamento da autoria dos artigos em revistas está por ser feito e merece um trabalho a parte.

Outro aspecto interessante a ser aqui observado é o que diz respeito a quem edita revistas. Isto pode ser observado de dois ângulos: (1) no geral, são instituições ou cursos que editam as revistas e não editoras; isto pelo menos no Brasil (2) não temos a tradição de um editor qualificado (treinado para este fim) e os Cursos ou as Instituições vão atribuindo a tarefa editorial, em rodízio, para coordenadores ou indivíduos que disponham de tempo para isso, quando de fato a editoração não pode ser feita de forma tão amadorística. Não temos ainda uma cultura sólida da editoração de revistas e do "editor" técnico.

Quantas revistas temos? Não existe ainda uma relação das revistas publicadas no Brasil na áreas de L\&L. ${ }^{5}$ Também não sabemos ainda como se acham as publicações em relação à sua indexação em nossas áreas. É provável que com o tempo tenhamos mais informaçôes e visibilidade sobre a questão. Há uma revista das áreas de L\&L produzida pela Graduação, mas resolvi incluí-la pelo simples fato de ser específica e ter uma política editorial muito clara.

Seria de utilidade saber quais são os órgãos mais importantes, de maior impacto e com mais trabalhos citados. Mas esse índice de citação não está nem perto de ser cogitado entre nós já que não indexamos as revistas.

\section{Proliferação de revistas}

Não é novidade, nem é de hoje a imensa pressão exercida pelas instituições de ensino e pesquisa e pelos órgãos de fomento no quesito publica-

\footnotetext{
5 Problema adicional é o que deveria ou não contar como revista nas áreas de L\&L. Veja-se o caso da revista CULT que tem como subtítulo "Revista Brasileira de Literatura". Trata-se de um órgão de L\&L no sentido técnico do termo ou apenas de uma revista comercial? Não incluí esse periódico mensal entre as revistas técnicas por pura falta de segurança quanto ao critério que deveria seguir. Mas pode-se incluí-la, desde que assim se decida. Outra revista é a Tempo Brasileiro, que em boa parte é uma revista também de L\&L, mas não tem o mesmo perfil em todos os casos. Há ainda algumas revistas de Educação que são muito mais voltadas para a área de L\&L do que para a educação como tal. Cito por exemplo Instrumento - Revista de Estudo e Pesquisa em Educação, produzida na UFJF, desde 1999.
} 
ções. Especialmente a partir do momento em que se instituiu a GED (Gratificação de Estímulo à Docência) em que a publicação passou a contar pontos indispensáveis. Não se trata de tê-las em quantidade, mas em qualidade. De certo modo, há um consenso entre a comunidade dos pesquisadores de que a revista científica é a forma mais rápida e eficiente para circulação das idéias. Daí sua proliferação entre nós. Mas uma proliferação sem controle e de qualidade discutível.

O levantamento anexo, com dados preliminares, provavelmente não completos, mostra um fato curioso e até agora desconhecido. A grande proliferação de revistas deu-se na década de 90, especialmente na sua segunda metade. Os mais antigos são dois do início dos anos 50, e nos anos 60 surgiram outros 2 , sendo que nos anos 70 foram criados 14 periódicos; nos anos 80 foram 21 e quase todos na primeira metade dos anos 80. Para muitos dos periódicos não foi possível identificar a data de início. É curiosa essa trajetória, pois sabemos que nos anos 70 surgiu a PG e entre $80-85^{6}$ deu-se o melhor período para a capacitação e equipagem da PG e depois disto foram os anos 94-98 com alguns convênios interessantes e sobretudo com a exigência de publicações para as avaliações em função da GED. Isto significa que reagimos ao sabor das verbas e das pressões e não por um planejamento de produção. Tudo indica que o aumento de produção reflete pressões institucionais e não necessariamente maior investimento na pesquisa por parte dos pesquisadores.

Deve-se, no entanto, observar que nos anos 90 aumentou consideravelmente o número de doutores, já que os Cursos de Doutorado quase que duplicaram nesse período. Assim, com o aumento de Cursos e de Doutores, bem como de eventos científicos, foi necessário dar evasão a toda essa produção. Por outro lado, notou-se também que muitos Cursos de PG iniciaram a publicação de artigos de teses e dissertações (transformação tese/dissertação em artigo pela maior facilidade de publicação.

\footnotetext{
6 Embora não tenha sido a única razão, mas certamente foi importante a criação da ANPOLL que muito contribuiu, com a formação dos GTs, para o aumento da produção científica e a proliferação de revistas. Também o fortalecimento de outras Associaçōes Científicas (ABRALIN, ABRALIC, $\mathrm{ALAB}$ ) e o surgimento de sociedades lingüísticas regionais, tais como o GEL, GELNE, ASSEL e outras, contribuiu para a ampliação de órgãos de publicação, já que cada qual tenta produzir sua revista.
} 
Não obstante todas essas circunstâncias, parece pouco aconselhável que cada Curso de PG tenha sua revista, pois isto acaba por originar uma infinidade de revistas em sua maioria paroquiais ${ }^{7}$. Um Conselho Editorial de caráter nacional e até mesmo internacional para a revista não é garantia de qualidade, pois tudo dependerá de como o editor usa seu conselho para pareceres. Não se trata de impedir o surgimento de revistas científicas, mas de estimular uma produção de qualidade. Já houve quem propusesse a fusão de revistas para que sobrevivessem poucas, porém boas. Não creio que se possa fazer uma tal proposta sem um estudo muito profundo da questão, pois isto equivaleria a tirar parte da liberdade de decisão dos programas de PG e limitar as iniciativas.

Seja como for, no futuro deveremos pensar em sistemas de produção que não tenham os Cursos como base de sustentação e sim as sociedades científicas, correntes teóricas ou grandes linhas temáticas. Poderia haver muitas revistas, mas todas com identidade. Além disso, ao invés de haver muitos títulos haveria maior número de fascículos anuais e regularidade na edição.

Como comprovação do que estou afirmando, é só surgir uma primeira crise séria de financiamento à PG e muitas das revistas atuais não serão mais editadas ou terão sua periodicidade comprometida.

Já é o momento de se fazer uma discussão mais completa a respeito das publicações em nossas áreas não só em relação às revistas, mas também em relação aos anais e aos livros e coletâneas de textos. Embora haja uma certa "exuberância" editorial nas nossas áreas, não se tem a menor idéia de seu quantitativo. Também aumentou a participação das editoras comerciais bem como das editoras universitárias. Seria interessante se alguém se dedicasse a esse levantamento nos anos 90 .

\section{Profissionalismo editorial}

Não são muitas as revistas científicas em L\&L que poderiam ser tidas como de produção, distribuição e cuidado profissionais. Muitas são

\footnotetext{
7 Ao se observar o panorama das revistas, pode-se imaginar que se trata de uma questão de prestígio institucional o fato de dispor de uma ou mais revistas. Pois isto é sempre indicado com orgulho em páginas centrais dos folhetos de divulgação das instituições. Segundo me consta há ainda cerca de 10 revistas em gestação neste momento e é provável que aqui faltem mais de duas dezenas, pois não considero este levantamento completo
} 
relativamente amadorísticas. Se tomarmos as revistas de Universidade renomadas do país, veremos que muitas das 128 revistas não têm ISSN indicado. A maioria não informa a periodicidade, algumas sequer trazem o endereço e 31 não tem a informação sobre o ano de início da publicação. Isto para ficar apenas no que se refere a um aspecto estritamente formal. $\mathrm{O}$ curioso é que há revistas que sequer apresentam o endereço para correspondência e não indicam a vinculação institucional. Não sabemos se são números avulsos ou não.

Quanto à padronização, em termos de cuidado na forma de citação, dados bibliográficos e marcas características, não se observa regularidade. Falta a muitas de nossas revistas um projeto gráfico, uma definição de tratamento textual e todo tipo de uniformização. Isto é lamentável e afasta nossas revistas do mercado internacional. Já o simples manuseio torna muitas destas revistas desagradáveis. Deve-se, no entanto, dizer que o cuidado vem aumentando sensivelmente e as revistas mais atuais já estão com formato e requisitos técnicos bem mais planejados.

Dois aspectos são preocupantes: primeiro, a falta de periodicidade e, segundo, a péssima distribuição e divulgação. Creio que ambos os aspectos estão juntos e são responsáveis pelo encalhe das revistas e por sua não circulação. Os programas de PG e todos os demais editores de revistas deveriam tomar a si o encardo de uma divulgação mais sistemática entre as instituições, bibliotecas e pesquisadores. Deveria ser criado algo assim como um sistema automático de troca ou intercâmbio entre todas as revistas existentes (pelo menos as institucionais), de maneira que isto propiciaria que todos dispusessem das coleçôes para consulta.

\section{Proposta para uma política de periódicos científicos em $L \& L$}

Propor uma política editorial para revistas científicas numa dada área é sempre um empreendimento temerário, mas necessário. Nas diversas oportunidades em que me encontrei com colegas e discuti a questão, ouvi posições muito variadas, mas duas delas foram recorrentes e quase opostas, podendo ser aqui preliminarmente discutidas como alternativas. São elas: 
a) deveria haver muitas revistas para que se pudesse publicar tudo o que se produz, já que não é fácil ter acesso às revistas consagradas, especialmente quando não se é de grandes centros ou não se freqüenta certos círculos;

b) deveria haver um número limitado de revistas para que só se publicasse o que é bom e não houvesse uma proliferação de trabalhos fracos ou inúteis.

Seguramente, as duas propostas têm seus prós e contras. Contudo, pondero que no caso de uma proliferação exagerada de revistas, como vem ocorrendo em nossas áreas no momento, teremos dificuldade de discernir entre o que é bom e o que não é. Uma mesma revista às vezes traz dois textos bons e 5 ruins, sendo que os dois bons se perdem porque a revista é tratada como ruim em seu todo. Por outro lado, de nada serve publicar de tudo já que isso não vai ajudar em nada além de ajudar os autores a terem currículos com títulos publicados. A multiplicidade sem avaliação é um problema sério porque não preserva a qualidade e só dá atenção para a quantidade. $\mathrm{O}$ argumento aduzido para a falta de acesso aos periódicos mais conhecidos e conceituados não é válido, pois basta ter um bom trabalho que ele terá colhida em bons periódicos. Não é necessário publicar 30 textos ruins ou medianos por ano. Bastam 3 ou 4 bons.

Quanto à política da qualidade, com redução do número de periódicos, trata-se de um ideal de difícil realização, pois cada curso quer ter sua identidade preservada. Além disso, parece-me que deveria haver uma cultura mais desenvolvida para a análise dos textos por pareceristas. Também seria necessário aumentar a periodicidade das revistas e torná-las mais profissionais no que tange à distribuição e assinaturas. A política editorial não deveria ser fechada ou então deveria haver revistas mais específicas de linhas teóricas ou de áreas de investigação. Um número reduzido ou uma política bem-pensada para os periódicos poderia disciplinar de maneira mais adequada a área. Mas isto teria o inconveniente do viés teórico predominante ou de correlaçóes de forças nem sempre equilibradas.

Como se nota, tanto uma como outra dessas duas linhas teria inconvenientes bastante acentuados. Penso, pois, que se deveria achar uma terceira via que fosse uma espécie de compromisso entre ambas as aqui citadas e com isto se faria uma política mais clara em relação aos periódicos. Imagino que se poderia lançar estas idéias para início de discussão: 
1. Nem todos os cursos precisam ter revistas científicas; seria possível unir vários cursos e fazer com que se produzissem revistas mais fortes e com periodicidade maior (ao invés de dois números anuais, fazer quatro, por exemplo).

2. Seria bom que houvesse mais revistas específicas de área (Letras e Lingüística separadamente), pois assim se teria uma distinção mais clara na orientação e nas políticas editoriais. Para as revistas hoje mistas, poderia-se prever números temáticos alternados.

3. As novas revistas a serem criadas poderiam se preferencialmente ligadas a Sociedades Científicas e não a instituições universitárias. Isto lhes daria uma identidade temática e uma linha de investigação mais definida.

4. Os financiamentos seriam canalizados para todas as revistas habilitadas. Haveria uma melhor distribuição e uso das verbas.

5. Deveria ser providenciada uma sistemática de distribuição das revistas, profissionalizando-as, talvez com a colaboração direta de editoras comerciais. Também poderia ser pensada uma forma de realizar um intercâmbio automático e sistemático de todas as revistas.

Nossa área ainda não despertou para a publicação editorial eletrônica. ${ }^{8} \mathrm{E}$ isto deverá acontecer em breve, pois não se admite hoje que uma área do conhecimento não tenha periódicos sistematicamente editados pela via eletrônica. Isto não equivale a apenas lançar na internet os trabalhos na forma como estão no papel. Trata-se de uma forma muito diferente de publicação. Falo em revistas eletrônicas com características hipertextuais e não em revistas atualmente impressas replicadas eletronicamente. Pois isto não seria suficiente. Este assunto é importante para o futuro. Seguramente, as revistas eletrônicas (reduplicação das atuais revistas em papel) é desejável pela facilidade que se teria em consultá-las, mas isso é pouco já que a tecnologia de revistas eletrônicas está bem mais avançada do que isso.

8 A revista D.E.L.T.A. encontra-se hoje na WEB, mas não se trata de uma revista eletronicamente produzida. Ela está lá apenas como reduplicação do texto em papel. 


\section{Palavras finais}

As observaçôes aqui trazidas servem como estímulo inicial para discussão. Imagino que este assunto é muito importante para que permaneça sem um debate mais amplo. Por isso mesmo estão sendo divulgadas estas reflexões mesmo que ainda iniciais.

De igual modo, a relação anexa é de suma importância pelo fato de estar divulgando pela primeira vez para a área uma listagem "quase-completa” dos periódicos existentes. Peço a todos os colegas que tiverem acesso a estes documentos, que me remetam informações complementares com correções (já que deve haver equívocos aqui) ou sugestôes para novos dados a serem incluídos.

\section{ANEXO \\ Relação das Revistas Científicas Brasileiras em Letras \& Lingüística}

\section{Luiz Antônio Marcuschi (UFPE) lamarcuschi@uol.com.br}

As revistas abaixo foram elencadas sem obedecer a qualquer tipo de ordem. Certamente, teria sido bom definir algum critério, por exemplo, uma separação por área (Letras num grupo e Lingüística em outro), mas isto é praticamente inviável, com exceção de alguns poucos casos, pois as revistas em sua maioria ainda continuam mistas. Também teria sido bom colocá-las numa ordem cronológica pelo seu ano de surgimento. Ocorre, no entanto, que não se tem o ano de início de muitas delas. Quando se dispuser de informações mais detalhadas sobre as revistas, será possível estabelecer critérios mais rigorosos e mais sistemáticos tanto para sua classificação como para sua avaliação. Agradeço aqui aos inúmeros colegas que me deram estas informações e à ABRALIN, à DELTA e à ANPOLL pelo estímulo no levantamento. 
(1)

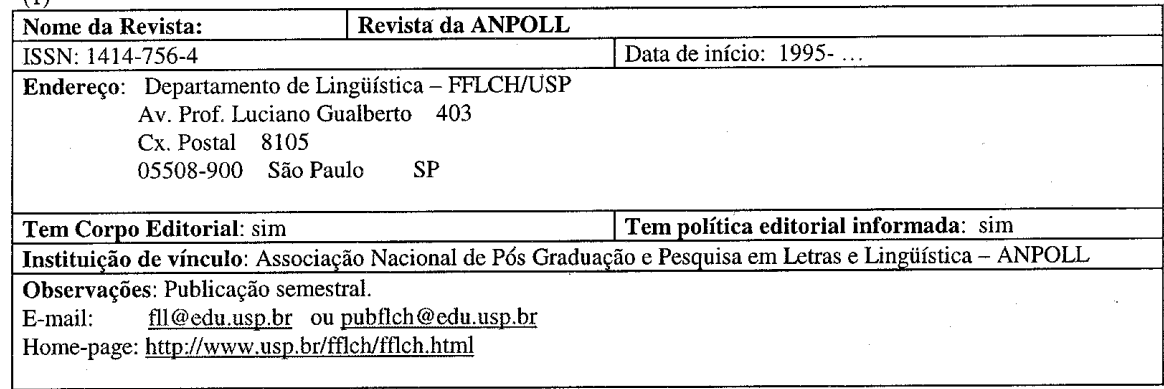

(2)

\begin{tabular}{|c|c|}
\hline Nome da Revista: & D.E.L.T.A - Documentação de Estudos em Lingüística Teórica e Aplicada \\
\hline ISSN: 0102-445 & Data de início: $1985-$ \\
\hline \multicolumn{2}{|c|}{$\begin{array}{l}\text { Endereço: Pontifícia Universidade Católica de São Paulo } \\
\text { Departamento de Lingüística } \\
\text { R. Monte Alegre, 984, } \\
\text { 05014-001 São Paulo SP }\end{array}$} \\
\hline \begin{tabular}{|l} 
Tem Corpo Editorial: $\operatorname{sim}$ \\
\end{tabular} & Tem política editorial informada: $\operatorname{sim}$ \\
\hline \multicolumn{2}{|c|}{ Instituição de vínculo: PUC-SP e ABRALIN } \\
\hline \multicolumn{2}{|c|}{$\begin{array}{l}\text { Observações: Publicação semestral, indexada internacionalmente (LLBA; MLA; ULRICH'S International } \\
\text { Periodicals Directory) } \\
\text { E-mail: delta@exatas.pucsp.br } \\
\text { Edição virtual: www.scielo.br/delta }\end{array}$} \\
\hline
\end{tabular}

(3)

\begin{tabular}{|c|c|}
\hline Nome da Revista: & güísticos \\
\hline ISSN: 0102-5767 & Data de início: $1978-\ldots$ \\
\hline $\begin{array}{l}\text { Endereço: UNICAMP-IEL Setor de Pu } \\
\text { Cx. Postal } 6045 \\
13081-970 \quad \text { Campinas }\end{array}$ & \\
\hline Tem Corpo Editorial: sim & Tem política editorial informada: sim \\
\hline Instituição de vínculo: Instituto de Estu & UNICAMP \\
\hline $\begin{array}{l}\text { Observações: semestral } \\
\text { E-mail: spublic@iel.unicamp.br } \\
\text { Home-page: http://www.unicamp.br/iel }\end{array}$ & 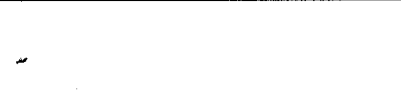 \\
\hline
\end{tabular}

(4)

\begin{tabular}{|c|c|}
\hline Boletim do Centro de Es & tudos Portugueses \\
\hline ISSN: 0101-7934 & Data de início: $1979-\ldots$ \\
\hline $\begin{array}{l}\text { Endereço: Faculdade de Letras - } \\
\text { Centro de Estudos Portugueses } \\
\text { Av. Antonio Carlos, } 6627 \text { Cidade universitária - } \\
\text { Pampulha } \\
\text { 31270-910 Belo Horizonte MG }\end{array}$ & L \\
\hline Tem Corpo Editorial: sim & Tem política editorial informada: sim \\
\hline \multicolumn{2}{|l|}{ Instituição de vínculo: FALE-UFMG } \\
\hline Observaçôes: & \\
\hline
\end{tabular}


(5)

\begin{tabular}{|l|l|}
\hline Nome da Revista: & Caderno de Letras \\
\hline ISSN: & Data de início: 1994 \\
\hline Endereço: Pontifícia Universidade Católica de Minas Gerais \\
Pró-Reitoria de Extensão \\
Av. D. José Gaspar, 500, \\
Coração Eucarístico, \\
Caixa Postal 1686 \\
30535-610 Belo Horizonte MG \\
\hline Tem Corpo Editorial: não \\
\hline Instituição de vínculo: Pontifícia Universidade Católica de Minas Gerais \\
\hline Observações: semestral - Tel (031) 319-1220 \\
\hline
\end{tabular}

(6)

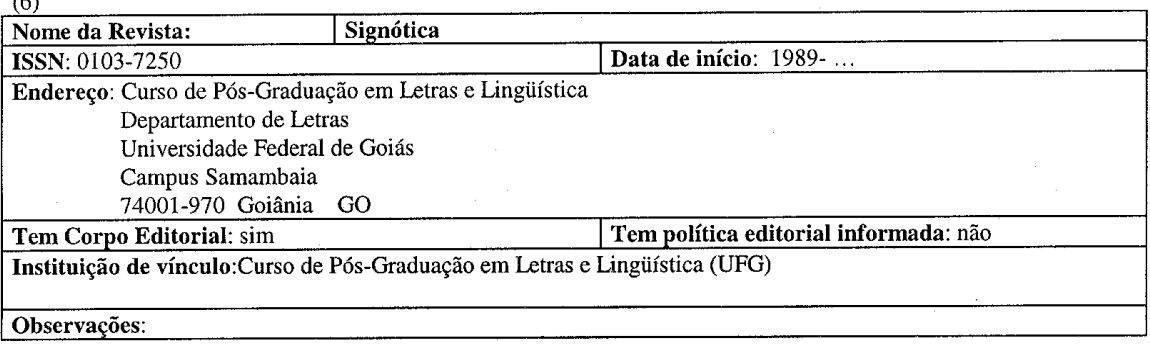

(7)

\begin{tabular}{|l|l|}
\hline Nome da Revista: & Leitura: Teoria \& Prática \\
\hline ISSN: 0102-387X & Data de início: 1981 \\
\hline Endereço: Leitura: Teoria \& Prática & \\
Associação de Leitura do Brasil & \\
Faculdade de Educação - UNICAMP \\
Cidade Universitária Zeferino Vaz \\
13081-970 Campinas SP \\
\hline Tem Corpo Editorial: sim & Tem política editorial informada: sim \\
\hline Instituição de vínculo: Associação de Leitura do Brasil \\
\hline
\end{tabular}

(8)

\begin{tabular}{|c|c|}
\hline Investigações - Lingüística & a e Teoria Literária \\
\hline ISSN: 0104-1320 & Data de início: 1979 \\
\hline $\begin{array}{l}\text { Endereço: Curso de Pós- Graduação em Letras e Lingüística } \\
\text { Centro de Artes e Comunicação } \\
\text { Universidade Federal de Pernambuco } \\
50670-901 \quad \text { Recife PE }\end{array}$ & 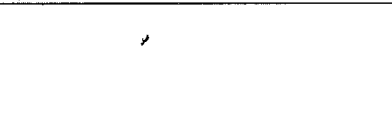 \\
\hline Tem Corpo Editorial: sim & Tem política editorial informada: $\operatorname{sim}$ \\
\hline \multicolumn{2}{|c|}{ Instituição de vínculo: Curso de Pós- Graduação em Letras e Lingüística (UFPE) } \\
\hline $\begin{array}{c}\text { Observações: Publicação semestral - Tel: (081) 3271-8312 } \\
\text { E-mail: pgletras@ @pd.ufpe.br }\end{array}$ & \\
\hline
\end{tabular}


(9)

\begin{tabular}{|l|l|}
\hline Nome da Revista: & \multicolumn{2}{|c|}{ Revista de Estudos da Linguagem } \\
\hline ISSN: 0104-0588 & Data de início: 1984-... \\
\hline Endereço: Universidade Federal de Minas Gerais - UFMG \\
Faculdade de Letras sl 4004 \\
Av. Antônio Carlos, 6627 \\
31270-910 Belo Horizonte MG \\
\hline Tem Corpo Editorial: sim \\
\hline Instituição de vínculo: Faculdade de Letras da UFMG \\
\hline Observações: semestral
\end{tabular}

(10)

\begin{tabular}{|l|l|}
\hline Nome da Revista: & ALFA - Revista de Lingüística \\
\hline ISSN: 0002-5216 & \multicolumn{2}{|c|}{ Data de início:1962-... } \\
\hline $\begin{array}{l}\text { Endereço: Instituto de Letras, Ciências Sociais e Educação } \\
\text { Estrada de Araraquara-Jaú } \\
14800-000 \text { Araraquara } \\
\text { Cx.P. } 174\end{array}$ \\
\begin{tabular}{l} 
Tem Corpo Editorial: sim \\
\hline Instituição de vínculo: Departamento de Letras -UNESP- Araraquara
\end{tabular} \\
\hline Observações:
\end{tabular}

(11)

\begin{tabular}{|l|l|}
\hline Nome da Revista: & \multicolumn{2}{|l|}{ The Especialist } & \multicolumn{2}{|l|}{} \\
\hline ISSN: 0102-7077 & Data de início:1980-... \\
\hline Endereço: Curso de Pós-Graduação em Lingüística Aplicada & -CEPRIL \\
PUC-SP & \\
R. Monte Alegre, 984 & SP \\
05014-000 São Paulo & Tem política editorial informada: sim \\
\hline Tem Corpo Editorial: sim & \\
\hline Instituição de vínculo: Curso de Pós-Graduação em Linguística Aplicada -CEPRIL \\
\hline
\end{tabular}

(12)

\begin{tabular}{|c|c|}
\hline Nome da Revista: & Em Aberto \\
\hline ISSN: 0104-1037 & Data de início: 1976 \\
\hline \multicolumn{2}{|c|}{$\begin{array}{c}\text { Endereço:S GAS - Quadra 607 - Lote 50- Asa Sul } \\
\text { 70919-970 Brasília DF }\end{array}$} \\
\hline Tem Corpo Editorial: não & Tem política editorial informada: não \\
\hline Instituição de vínculo: INE & (2) \\
\hline
\end{tabular}

(13)

\begin{tabular}{|c|c|}
\hline Nome da Revista: & Aplicada \\
\hline ISSN: $0103-1813$ & Data de início: $1983-\ldots$ \\
\hline $\begin{array}{l}\text { Endereço: Departamento de Lingüística } \\
\text { Setor de Publicações } \\
\text { Cx. Postal } 6045 \\
\text { 13081-970 Campinas SP }\end{array}$ & CAMP \\
\hline Tem Corpo Editorial: sim & Tem política editorial informada: $\operatorname{sim}$ \\
\hline \multicolumn{2}{|c|}{ Instituição de vínculo: Departamento de Lingüística Aplicada - IELUUNICAMP } \\
\hline $\begin{array}{l}\text { Observações: semestral } \\
\text { E-mail: spublic@iel.unicamp.br } \\
\text { Home-page: http } / / \text { www.unicamp.br/iel }\end{array}$ & \\
\hline
\end{tabular}


(14)

\begin{tabular}{|l|l|}
\hline Nome da Revista: & \multicolumn{1}{|c|}{ Estudos Lingüísticos - GEL } \\
\hline ISSN: $1413-0939$ & Data de início: 1978 \\
\hline Endereço: variável de acordo com o local da Diretoria do GEL \\
\hline Tem Corpo Editorial: sim & Tem política editorial informada: sim \\
\hline \begin{tabular}{l} 
Instituição de vínculo: Grupo de Estudos Linguísticos do Estado de São Paulo \\
\hline Observações: Publica, em geral, os anais do Congresso do GEL \\
O endereço é o da Diretoria em exercício
\end{tabular} \\
\hline
\end{tabular}

(15)

\begin{tabular}{|c|c|c|}
\hline \multirow{2}{*}{\multicolumn{2}{|c|}{\begin{tabular}{l|l} 
Nome da Revista: & Letras de Hoje \\
ISSN: $0101-3335$ & \\
\end{tabular}}} & \\
\hline & & Data de início: $1967-\ldots$ \\
\hline \multicolumn{3}{|c|}{ 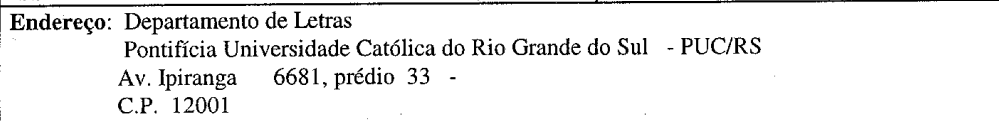 } \\
\hline \multicolumn{2}{|c|}{ Tem Corpo Editorial: sim } & Tem política editorial informada: sim \\
\hline \multicolumn{3}{|c|}{ Instituição de vínculo: Departamento de Letras - PUC-RS } \\
\hline
\end{tabular}

(16)

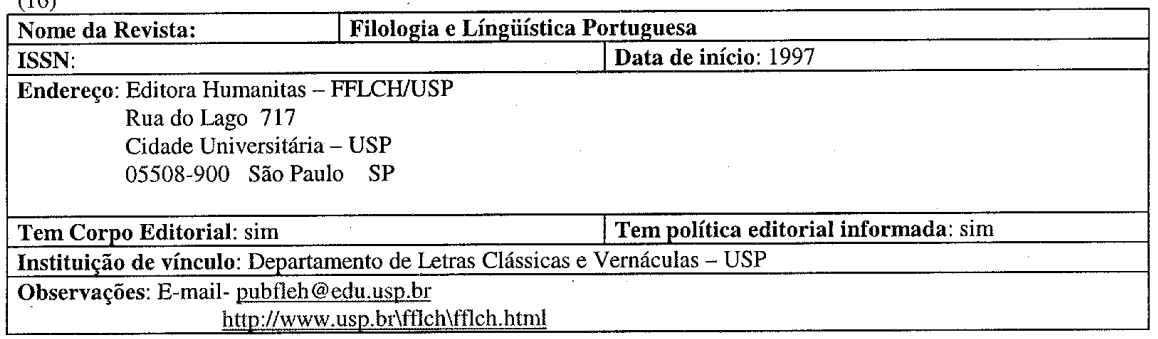

(17)

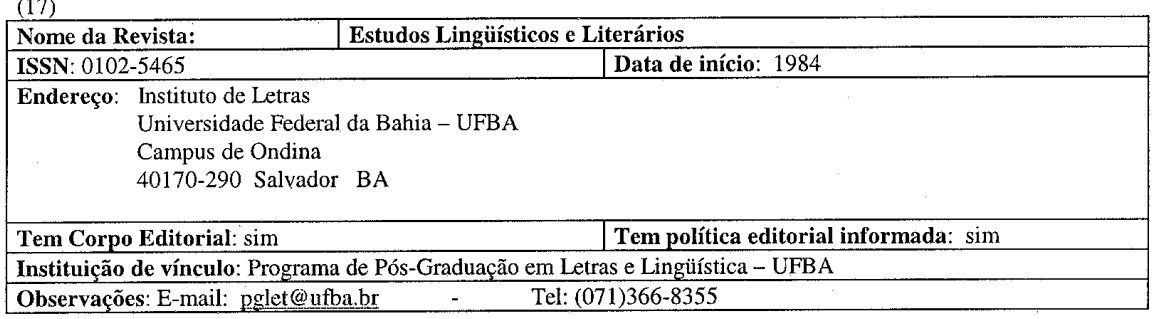

(18)

\begin{tabular}{|l|l|}
\hline Nome da Revista: & \multicolumn{2}{|l|}{ Interfaces } & Data de início: 1995 \\
\hline ISSN: & \multicolumn{2}{|l|}{} \\
\hline Endereço: & Universidade Federal do Rio de Janeiro \\
Centro de Letras e Artes & \\
Coordenação de Integração Acadêmica de Pós-Graduação Universitária \\
Cidade Universitária - Edifício da Reitoria - Térreo \\
21949-900 Rio de Janeiro RJ \\
\begin{tabular}{l} 
Tem Corpo Editorial: sim \\
\hline Instituição de vínculo: Centro de Letras e Artes - UFRJ
\end{tabular} \\
\hline Observações: Tel: (021)290-2112 \\
\hline
\end{tabular}


(19)

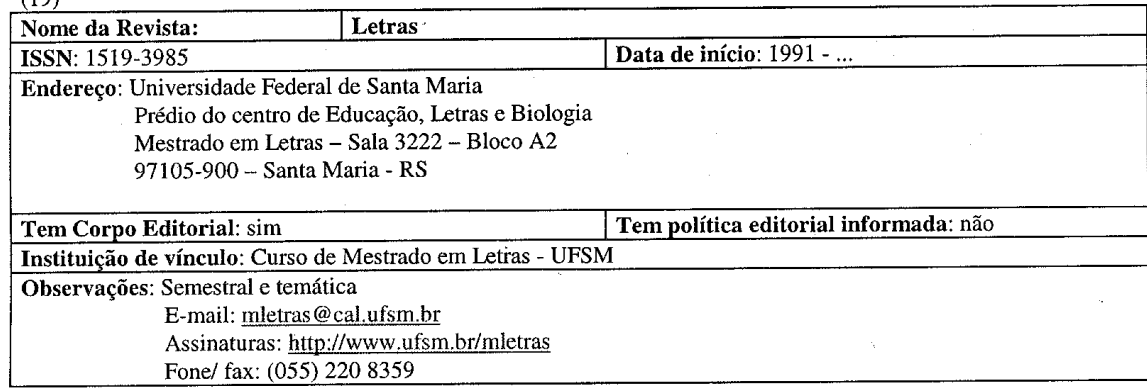

(20)

\begin{tabular}{|l|l|}
\hline Nome da Revista: & \multicolumn{1}{|l|}{ Revista Brasileira de Lingüística } \\
\hline ISSN: & Data de início: 1987 \\
\hline Endereço: Sociedade Brasileira de Professores de Lingüística (SBPL) \\
Av. Prof. Luciano Gualberto 403 Bloco I térreo \\
$\begin{array}{l}\text { Cidade Universitária - Cx. Postal } 8105 \\
\text { 05508-900 São Paulo SP }\end{array} \quad$ Tem política editorial informada: sim \\
\hline Tem Corpo Editorial: sim \\
\hline Instituição de vínculo: Sociedade Brasileira de Professores de Lingüística (SBPL) \\
\hline Observações: semestral
\end{tabular}

(21)

\begin{tabular}{|l|l|}
\hline Nome da Revista: & \multicolumn{2}{|l|}{ Linguagens, Educação e Sociedade } \\
\hline ISSN: & Data de início: \\
\hline Endereço: Coordenação de Curso de Mestrado em Educação \\
Centro de Ciências da Educação \\
Campus da Iningá \\
64049-550 Teresina PI $\quad$ PI \\
\hline Tem Corpo Editorial: \\
\hline Instituição de vínculo: \\
\hline Observações: \\
\hline
\end{tabular}

(22)

\begin{tabular}{|l|l|}
\hline Nome da Revista: & Miscelânea \\
\hline
\end{tabular}

\begin{tabular}{l|l}
\hline ISSN: $0104-3420$ & Data de início: 1993
\end{tabular}

Endereço: Revista de Pós-Graduação em Letras: Teoria Literária, Literatura Comparada e

Literaturas de Língua Portuguesa

Faculdade de Ciências e Letras - UNESP - Cx. Postal 335

19899-000 Assis SP

Tem Corpo Editorial: $\operatorname{sim}$

Tem política editorial informada:

Instituição de vínculo: Departamento de Literatura - UNESP-Assis

Observações:

(23)

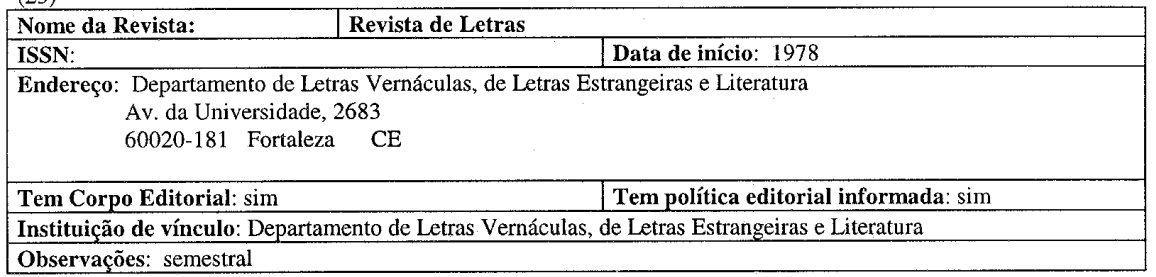


(24)

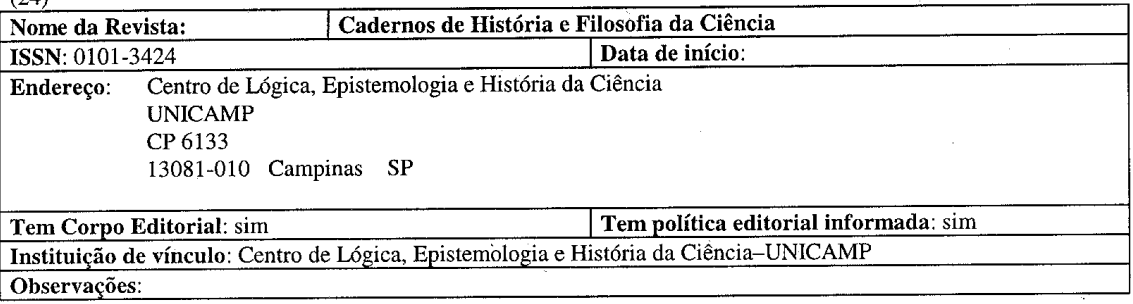

(25)

\begin{tabular}{|l|l|}
\hline Nome da Revista: & Gávea \\
\hline ISSN: & Data de início: 1984 \\
\hline Endereço: & Revista de História da Arte e Arquitetura \\
& Pontifícia Universidade Católica do Rio de Janeiro \\
Departamento de História & \\
R. Marquês de São Vicente, 225 sl $515-\mathrm{F}$ \\
22453-900 Rio de Janeiro RJ \\
\hline Tem Corpo Editorial: SIM & Tem política editorial informada: \\
\hline Instituição de vínculo: Departamento de História - UFRJ \\
\hline Observações: semestral - Fax: (021) 259-1642 \\
\hline
\end{tabular}

(26)

\begin{tabular}{|l|l|}
\hline Nome da Revista: & Odisséia \\
\hline ISSN: 1413 - 4640 & Data de início: 1994 \\
\hline Endereço: Universidade Federal do Rio Grande do Norte & \\
Centro de Ciências Humanas, Letras e Artes \\
Campus Universitário \\
BR -101 s/n Lagoa Nova \\
$59072-970$ Natal RN \\
\hline Tem Corpo Editorial: sim & Tem política editorial informada: sim \\
\hline Instituição de vínculo: Centro de Ciências Humanas, Letras e Artes \\
\hline Observaçôes: semestral \\
E-mail: odisseia@echla.ufrn.br \\
\hline
\end{tabular}

(27)

\begin{tabular}{|l|l|}
\hline Nome da Revista: & \multicolumn{2}{|l|}{ Estudos Anglo-Americanos ABRAPUI } \\
\hline ISSN: 0102-4906 & Data de início: 1977 \\
\hline $\begin{array}{l}\text { Endereço: Caixa Postal } 164 \\
\text { 15001 -000 São José do Rio Preto SP }\end{array}$ \\
\hline \begin{tabular}{l} 
Tem Corpo Editorial: sim \\
\hline Instituição de vínculo: ABRAPUI
\end{tabular} \\
\hline Observações:
\end{tabular}

(28)

\begin{tabular}{|l|l|}
\hline Nome da Revista: & RL Revista Literária \\
\hline ISSN: & Data de início: \\
\hline $\begin{array}{l}\text { Endereço: Centro de Extensão da Faculdade de Letras da UFMG } \\
\text { Av. Antônio Carlos, 6627 sl L 2000 - } 2 \text { andar } \\
\text { 31270-000 Belo Horizonte MG }\end{array}$ \\
\hline Tem Corpo Editorial: não & Tem política editorial informada: não \\
\hline Instituição de vínculo: Corpo Discente da UFMG \\
\hline Observações:
\end{tabular}


(29)

\begin{tabular}{|l|l|}
\hline Nome da Revista: & Letras \& Letras \\
\hline ISSN: $0102-3527$ & Data de início: 1985 \\
\hline Endereço: & $\begin{array}{l}\text { Departamento de Letras e Departamento de Línguas Estrangeiras Modernas } \\
\text { Universidade Federal de Uberlândia } \\
38400-902 \text { Uberlândia MG }\end{array}$ \\
\hline \\
Tem Corpo Editorial: sim & Tem política editorial informada: sim \\
\hline Instituição de vínculo: Departamento de Letras e de Línguas Estrangeiras Modernas \\
\hline Observações: Tel - (034) 235-2888 R. 162
\end{tabular}

(30)

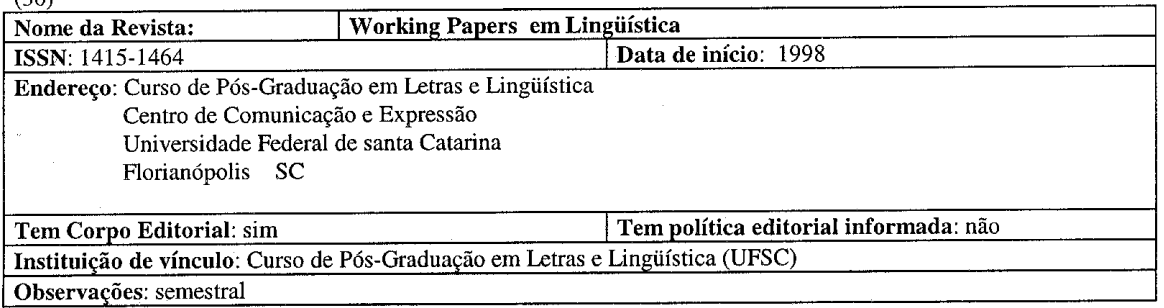

(31)

\begin{tabular}{|c|c|}
\hline Nome da Revista: & Revista Philologus - O Filólogo de Plantão \\
\hline ISSN: $1423-6457$ & \begin{tabular}{|l|l|} 
& Data de início: 1995 \\
\end{tabular} \\
\hline \multicolumn{2}{|c|}{$\begin{array}{l}\text { Endereço: Círculo Fluminense de Estudos Filológicos e Lingüísticos (CiFEFiL) } \\
\text { Rua Visconde de Noterói } 512 \text { /97 } \\
\text { 20943-000 Rio de Janeiro RJ }\end{array}$} \\
\hline Tem Corpo Editorial: sim & Tem política editorial informada: $\operatorname{sim}$ \\
\hline \multicolumn{2}{|c|}{ Instituição de vínculo: Círculo Fluminense de Estudos Filológicos e Lingüísticos (CiFEFiL) } \\
\hline $\begin{array}{r}\text { Observações: quadrimestra } \\
\text { E-mail: pereira } \\
\text { Home-page: } \mathrm{wr}\end{array}$ & $\frac{\mathrm{br}}{\operatorname{logia} . o r g . b r}$ \\
\hline
\end{tabular}

(32)

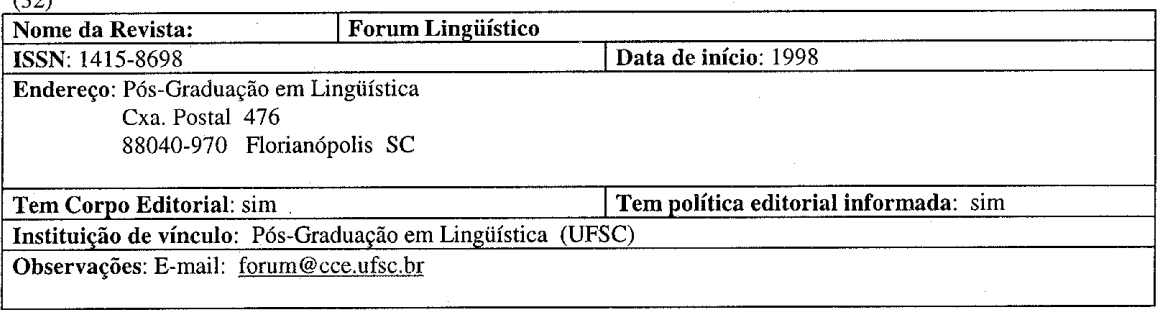

(33)

\begin{tabular}{|l|l|}
\hline Nome da Revista: & Confluência \\
\hline ISSN: & Data de início: \\
\hline Endereço: HVF - Arte e Cultura & R. Salvador Garcia, 39 $\begin{array}{l}\text { Butantã } \\
\text { 05503-030 São Paulo SP }\end{array}$ \\
\hline Tem Corpo Editorial: sim & Tem política editorial informada: não \\
\hline Instituição de vínculo: Departamento de Lingüística \\
\hline Observações:
\end{tabular}


(34)

\begin{tabular}{|l|l|}
\hline Nome da Revista: & \multicolumn{1}{|c|}{ Comunicação e Educação } \\
\hline ISSN: 0104-6829 & Data de início: \\
\hline Endereço: & CCA - ECA - USP \\
Av. Prof. Lúcio Martins Rodrigues, 443, Bloco Central, \\
Cidade Universitária - USP \\
05508-900 São Paulo SP \\
Tem Corpo Editorial: sim & Tem política editorial informada: sim \\
\hline Instituição de vínculo: Departamento de Comunicações e Artes - USP \\
\hline Observações:
\end{tabular}

(35)

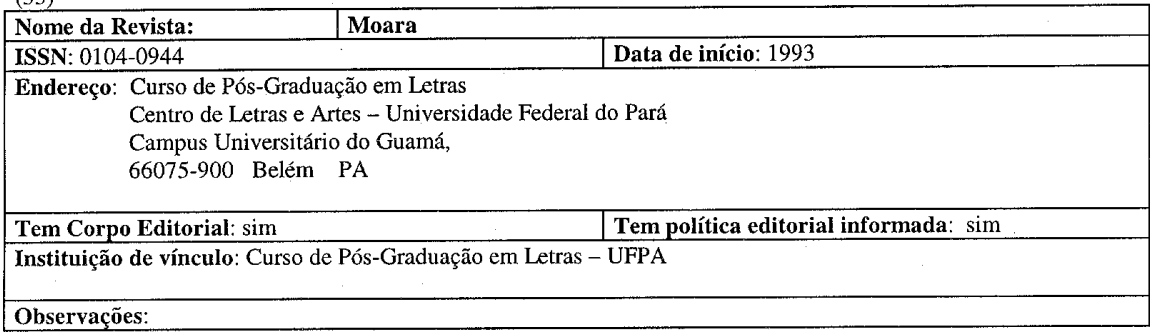

(36)

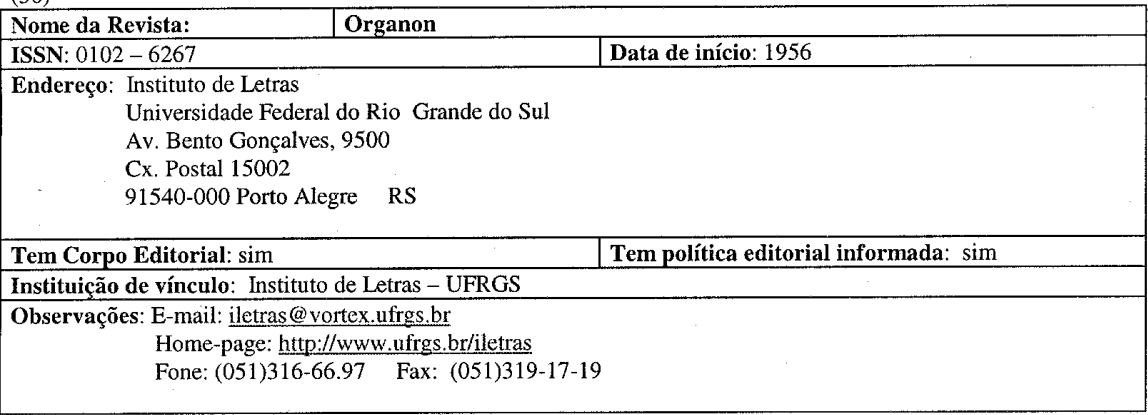

(37)

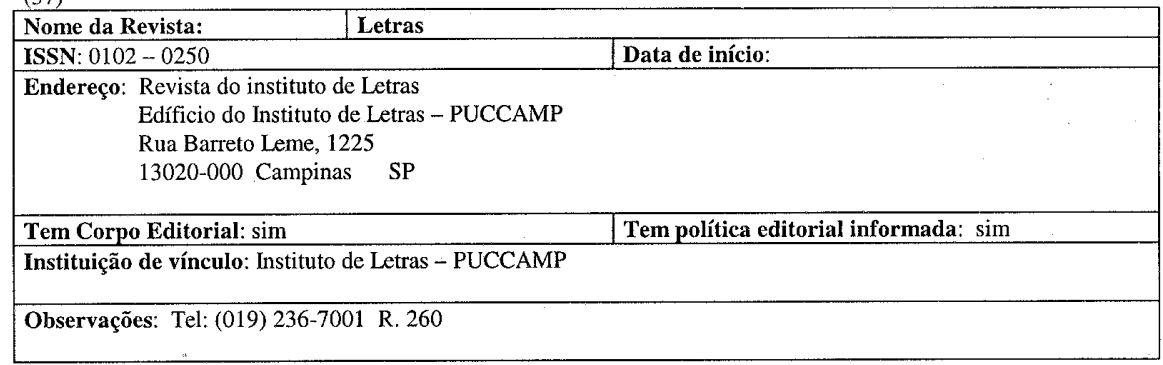


(38)

\begin{tabular}{|l|l|}
\hline Nome da Revista: & \multicolumn{2}{|l|}{ Trans/form/ação } & Data de início: 1975 \\
\hline ISSN: 0101 - 3173 & \\
\hline Endereço: Faculdade de Filosofia e Ciências \\
$\begin{array}{l}\text { Av. Hygino Muzzi Filho, } 737 \\
17500-000 \text { Marília SP }\end{array}$ \\
\hline \begin{tabular}{l} 
Tem Corpo Editorial: sim \\
\hline Instituição de vínculo: Faculdade de Filosofia e Ciências
\end{tabular} \\
\hline Observações: interrompida em 1976 voltou a publicar em 1980. \\
\hline
\end{tabular}

(39)

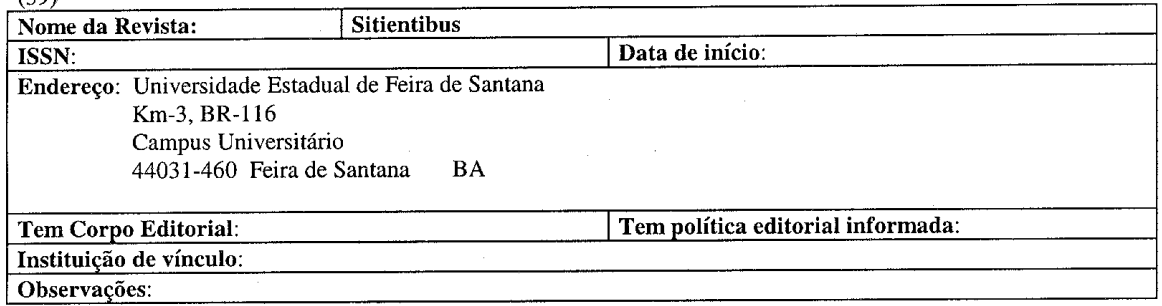

(40)

Nome da Revista:

ISSN:

O Eixo e a Roda -Revista de Literatura Brasileira

Endereço: Departamento de Letras Vernáculas

Data de início: 1983

Faculdade de Letras da UFMG

Rua Carangola $288,7^{\circ}$ andar

30000-000 Belo Horizonte MG

Tem Corpo Editorial: sim

Tem política editorial informada: não

Instituição de vínculo: Departamento de Letras Vernáculas - UFMG

Observações:

(41)

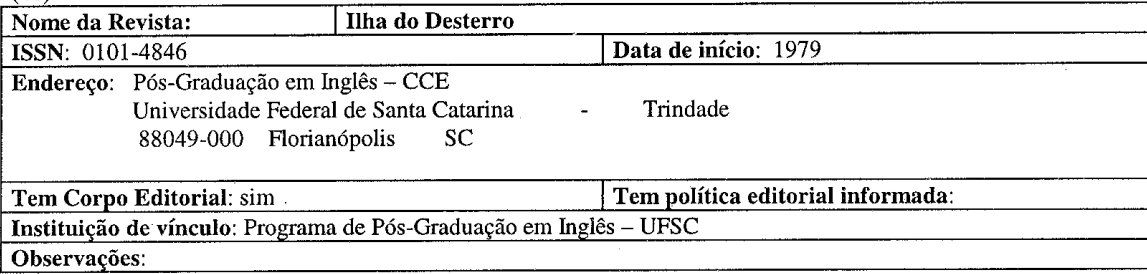

(42)

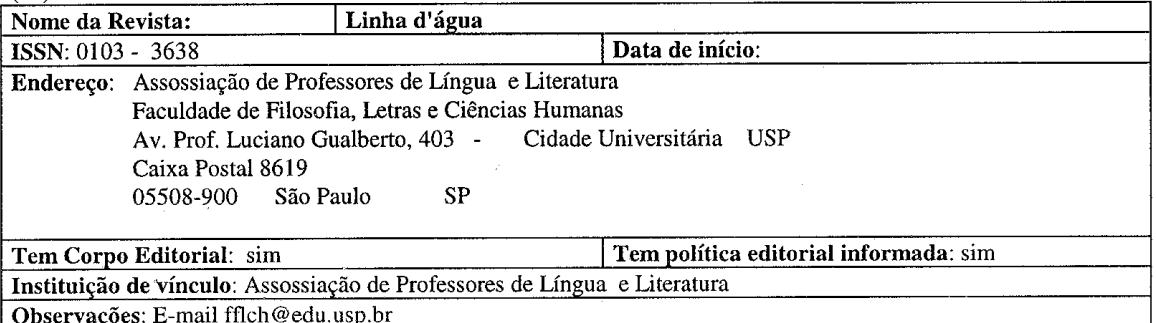


(43)

\begin{tabular}{|c|c|}
\hline Nome da Revista: & e Sociedade \\
\hline ISSN: 0104-9712 & Data de início: 1995 \\
\hline $\begin{array}{l}\text { Endereço: Departamento de Lingüistica } \\
\text { Universidade de Brasília } \\
70910-900 \text { Brasília DF }\end{array}$ & Vernáculas \\
\hline Tem Corpo Editorial: sim & Tem política editorial informada: sim \\
\hline
\end{tabular}

(44)

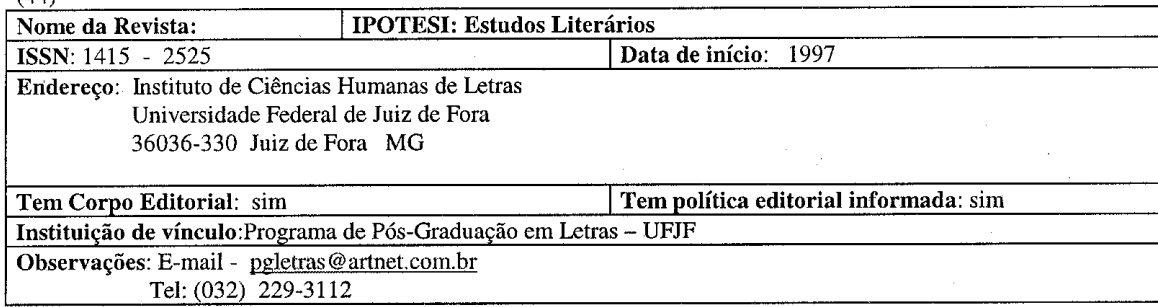

(45)

\begin{tabular}{|c|c|}
\hline VEREDAS: Revista de F & studos Lingüísticos \\
\hline ISSN: $1415-2533$ & Data de início: 1997 \\
\hline \multicolumn{2}{|c|}{ 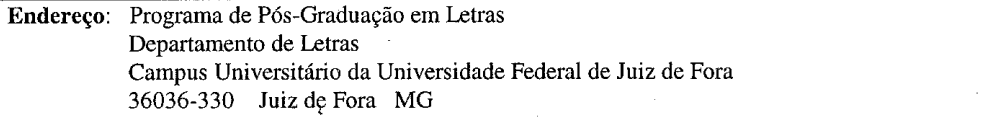 } \\
\hline Tem Corpo Editorial: sim & Tem política editorial informada: sim \\
\hline \multicolumn{2}{|c|}{ Instituição de vínculo:Programa de Pós-Graduação em Letras /Mestrado em Linguíística } \\
\hline $\begin{array}{l}\text { Observações: E-mail: pgletras@artnet.com.br } \\
\qquad \begin{array}{ll}\text { Tel: }(032) & 229-3112 \quad \text { fax: (032) } 229-3110\end{array}\end{array}$ & \\
\hline
\end{tabular}

(46)

\begin{tabular}{|l|l|}
\hline Nome da Revista: & Scripta \\
\hline ISSN: & Data de início: 1997 \\
\hline Endereço: Centro de Estudos Luso-Afro-Brasileiros & \\
& Pontifícia Universidde Católica de Minas Gerais - PUC-MG \\
Av. Dom José Gaspar 50 Prédio 04, sala 103 & \\
30525-610 Belo Horizonte MG & Tem política editorial informada: sim \\
\hline Tem Corpo Editorial: sim & \\
\hline Instituição de vínculo: PUC-MG & \\
\hline Observações: semestral
\end{tabular}

(47)

\begin{tabular}{|l|l|}
\hline Nome da Revista: & A Cor das Letras \\
\hline ISSN: & Data de início: 1997 \\
\hline Endereço: & Departamento de Letras e Artes \\
Universidade Estadual de Feira de Santana \\
Feira de Santana BA
\end{tabular}


(53)

\begin{tabular}{|l|l|}
\hline Nome da Revista: & Papia : \\
\hline ISSN: & Data de início: 1993 \\
\hline $\begin{array}{l}\text { Endereço: } \\
\text { Departamento de Lingüística, Línguas Clássicas e Vernáculas } \\
\text { Universidade de Brasília } \\
70910-900 \text { Brasília DF }\end{array}$ \\
\hline Tem Corpo Editorial: & Tem política editorial informada: \\
\hline Instituição de vínculo: & \\
\hline Observaços: &
\end{tabular}

(54)

\begin{tabular}{|l|l|}
\hline Nome da Revista: & \multicolumn{2}{|l|}{ Linguagem - Revista para estudos de língua e literatura } \\
\hline ISSN: & Data de início: 1983 \\
\hline Endereço: & $\begin{array}{l}\text { Rua Monte Alegre } 984 \text { sala 44 } \\
\text { Pontif́́cia Universidade Católica de São Paulo }\end{array}$ \\
& PUC-SP \\
$05014-000$ - São Paulo SP & \\
\hline Tem Corpo Editorial: & Tem política editorial informada: \\
\hline Instituição de vínculo: & \\
\hline Observações: &
\end{tabular}

(55)

\begin{tabular}{|l|l|}
\hline Nome da Revista: & Revista Camoniana \\
\hline ISSN: & Data de início: \\
\hline Endereço: Centro de Estudos Portugueses FFLCH & \\
& Departamento de Letras - USP \\
Cidade Universitária - USP & \\
C. Postal 8105 \\
05508-900 São Paulo SP
\end{tabular}

(56)

Nome da Revista:

ISSN:

Revista de Estudos Árabes

Endereço: Centro de Estudos Árabes

Data de início:

Faculdade de Filosofia, Letras e Ciêncisa Humanas - USP

Av. Prof. Luciano Gualberto 403

05508-900 São Paulo SP

Tem Corpo Editorial: sim

Tem política editorial informada: não

Instituição de vínculo: Centro de Estudos Árabes - FFLCH-USP

Observações:

(57)

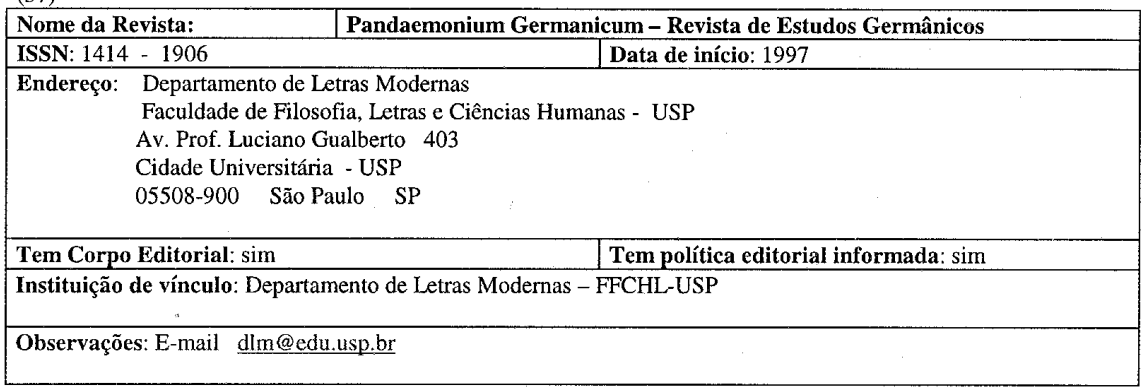


(58)

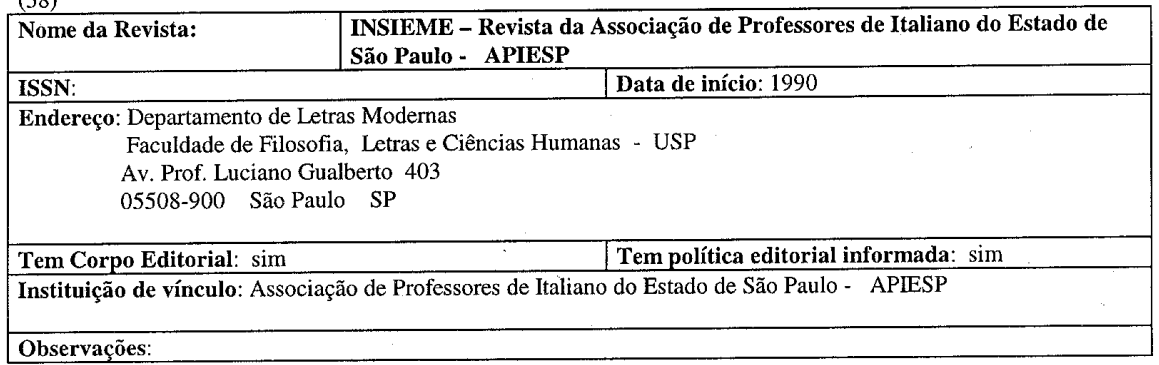

(59)

\begin{tabular}{|l|l|}
\hline Nome da Revista: & \multicolumn{1}{|l|}{ Revista de Italianística } \\
\hline ISSN: & Data de início: \\
\hline Endereço: & $\begin{array}{l}\text { Departamento de Letras Modernas } \\
\text { Faculdade de Filosofia, Letras e Ciências Humanas - USP } \\
\text { Av. Luciano Gualberto 403 } \\
\text { 05508-900 São Paulo SP }\end{array}$ \\
\hline Tem Corpo Editorial: sim & Tem política editorial informada: sim \\
\hline Instituição de vínculo: DLM - FFCHL-USP \\
\hline Observações: anual - Tel: (011) 210-2325
\end{tabular}

(60)

\begin{tabular}{|l|l|}
\hline Nome da Revista: & Revista de Estudos Orientais \\
\hline ISSN: & Data de início: 1997- \\
\hline Endereço: Departamento de Línguas Orientais & \\
Faculdade de Filosofia, Letras e Ciências Humanas - USP \\
Av. Prof. Luciano Gualberto \\
40305508-900 São Paulo SP \\
\hline Tem Corpo Editorial: sim \\
\hline Instituição de vínculo: Departamento de Línguas Orientais - USP \\
\hline Observações: E-mail - flo@edu.usp.br \\
\hline
\end{tabular}

(61)

\begin{tabular}{|l|l|}
\hline Nome da Revista: & \multicolumn{2}{|c|}{ MAGMA - Revista da Pós-Graduação } \\
\hline ISSN: 0104 - 6330 & Data de início: \\
\hline Endereço: & Departamento de Teoria Literária e Literatura Comparada \\
Faculdade Filosofia, Letras e e Ciências Humanas - USP \\
Av. Prof. Luciano Gualberto \\
40305508-900 São Paulo SP \\
\hline $\begin{array}{l}\text { Tem Corpo Editorial: sim } \\
\text { Literatura Comparada - USP }\end{array}$ \\
\hline \begin{tabular}{l} 
Observações: E-mail - fll@org.usp.br \\
\hline
\end{tabular}
\end{tabular}


(62)

\begin{tabular}{|l|l|}
\hline Nome da Revista: & Literatura e Sociedade -Revista de teoria Literária e Literatura Comparada \\
\hline ISSN: & Data de início: 1997 - \\
\hline Endereço: & Departamento de Teoria Literária e Literatura Comparada \\
Faculdade de Filosofia, Letras e ciências Humanas - USP \\
Av. Prof. Luciano Gualberto \\
40305508-900 São Paulo SP \\
\hline Tem Corpo Editorial: & Tem política editorial informada: \\
\hline Instituição de vínculo: \\
\hline Observações:
\end{tabular}

\section{Observações:}

(63)

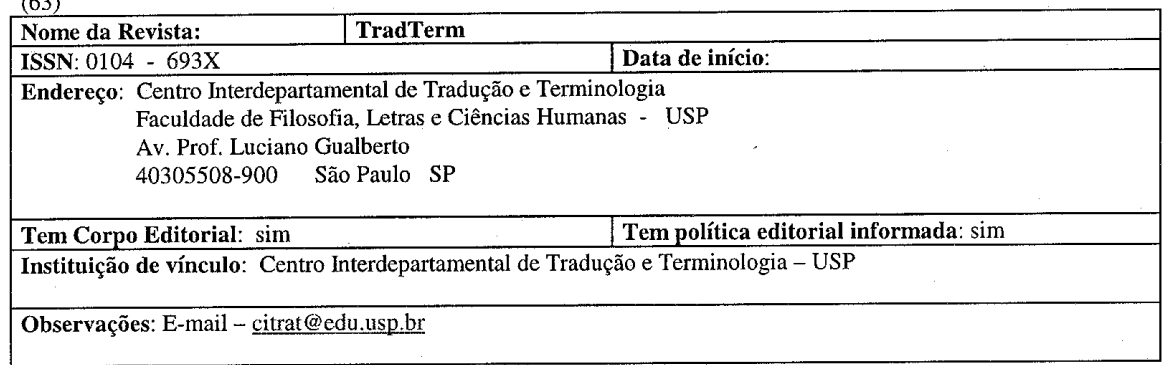

(64)

\begin{tabular}{|l|l|}
\hline Nome da Revista: & \multicolumn{2}{|l|}{ Alea: Estudos Neolatinos } \\
\hline ISSN: $1517-106 \mathrm{X}$ & Data de início: 1999 \\
\hline Endereço: Programa de Pós-Graduação em Letras Neolatinas \\
Faculdade de Letras - UFRJ \\
Av. Brigadeiro Trompovsky, s/n - Ilha do Fundão \\
21941-590 Rio de Janeiro RJ \\
\hline Tem Corpo Editorial: sim & Tem política editorial informada: sim \\
\hline Instituição de vínculo: Programa de Pós-Graduação em Letras Neolatinas - UFRJ \\
\hline Observaçães: E-mail - alea@letras.ufri.br \\
http://www.geocities.corn/neolatinas
\end{tabular}

(65)

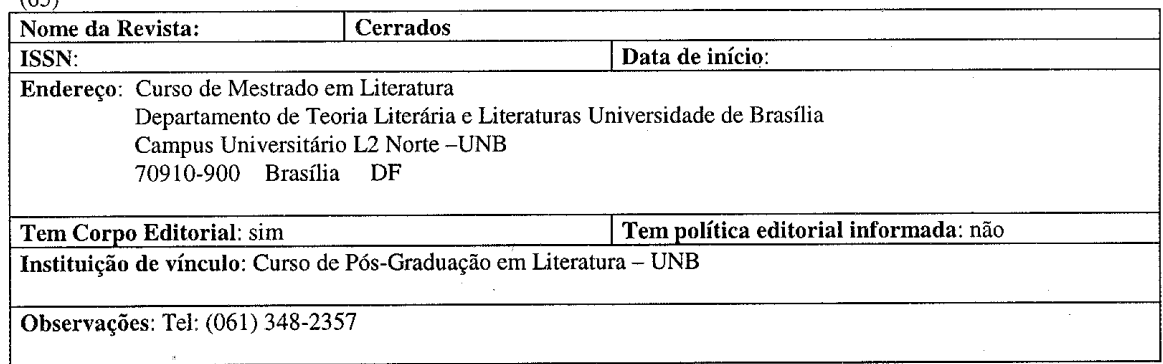


(66)

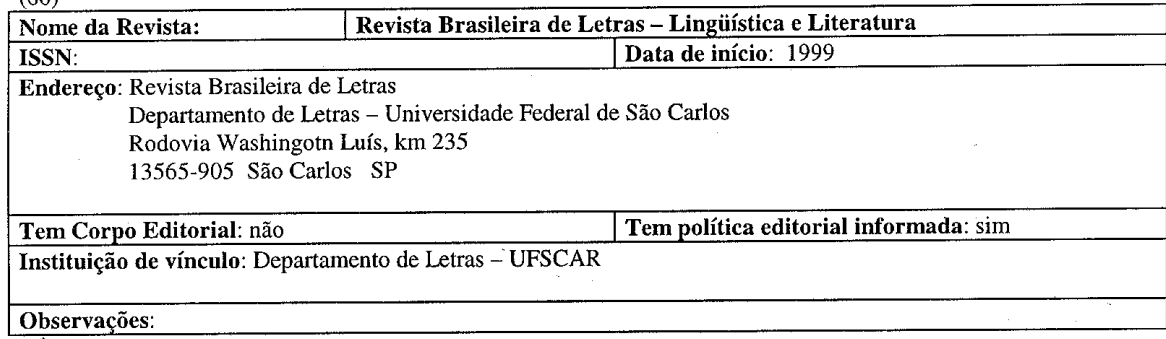

(67)

\begin{tabular}{|c|c|}
\hline Linguagem \& Ensino & \\
\hline ISSN: $1415-1928$ & Data de início: 1998 \\
\hline $\begin{array}{l}\text { Endereço: } \text { Mestrado em Letras } \\
\text { Universidade Católica de Pelotas } \\
\text { Rua Felix da Cunha } 412 \\
96010-000 \text { Pelotas RS }\end{array}$ & \\
\hline Tem Corpo Editorial: sim & Tem política editorial informada: sim \\
\hline \multicolumn{2}{|c|}{ Instituição de vínculo: Mestrado em Letras da Universidade Católica de Pelotas } \\
\hline $\begin{array}{l}\text { Observações: E-mail: } \\
\text { Homepage: hoslet@atlas.ucpel.tche.br } \\
\text { hit/atlas.ucpel.tche.br/ poslet }\end{array}$ & e.htm \\
\hline
\end{tabular}

(68)

\begin{tabular}{|c|c|c|}
\hline Nome da Revista: & Gragoatá & \\
\hline ISSN: $1413-9073$ & & Data de início: \\
\hline $\begin{array}{l}\text { Endereço: Av. Visconde do Ri } \\
\text { Campus do Gragoat } \\
\text { Bloco C - Sala } 501 \\
24220-200 \text { Niterói }\end{array}$ & $\begin{array}{l}\text { Branco s/n } \\
\text { - UFF } \\
\text { RJ }\end{array}$ & \\
\hline Tem Corpo Editorial: sim & & Tem política editorial informada: sim \\
\hline Instituição de vínculo: Institut & de Letras - UFF & \\
\hline
\end{tabular}

(69)

\begin{tabular}{|l|l|}
\hline Nome da Revista: & \multicolumn{2}{|l|}{ SIGNUM -Estudos da Linguagem } \\
\hline ISSN: $1516-3085$ & Data de início: 1998 \\
\hline Endereço: Revista Signum & \\
Programa de Pós-Graduação em Letras \\
$\begin{array}{l}\text { C.P. } 6001 \\
86051-990 \text { Londrina PR }\end{array}$ \\
\hline Tem Corpo Editorial: sim & Tem política editorial informada: sim \\
\hline Instituição de vínculo: Programa de Pós-Graduação em Letras - Universidade Estadual de Londrina \\
\hline $\begin{array}{c}\text { Observaçóes: E-mail: eduel@ @pd.uel.br } \\
\text { Publicação anual }\end{array}$ \\
\hline
\end{tabular}


(70)

\begin{tabular}{|c|c|}
\hline Nome da Revista: & Boletim da Associação Brasileira de Lingüística \\
\hline ISSN: $0102-7158$ & \begin{tabular}{l|l|} 
& Data de início: 1981 \\
\end{tabular} \\
\hline \multicolumn{2}{|c|}{ Endereço: Variável, dependendo do local da Diretoria. } \\
\hline Tem Corpo Editorial: não & Tem política editorial informada: não \\
\hline \multicolumn{2}{|c|}{ Instituição de vínculo: ABRALIN } \\
\hline
\end{tabular}

(71)

\begin{tabular}{|l|l|}
\hline Nome da Revista: & \multicolumn{2}{|l|}{ Ensino de Línguas - Série Cadernos } \\
\hline ISSN: 0102 - 2040 & Data de início: \\
\hline Endereço: EDUC - Editora da PUC-SP \\
R. Monte Alegre 984 \\
C.P. 7982 \\
05014-000 São Paulo SP \\
\hline Tem Corpo Editorial: sim & Tem política editorial informada: não \\
\hline Instituição de vínculo: PUC-SP \\
\hline Observações: Tel: (011) 263-0211
\end{tabular}

(72)

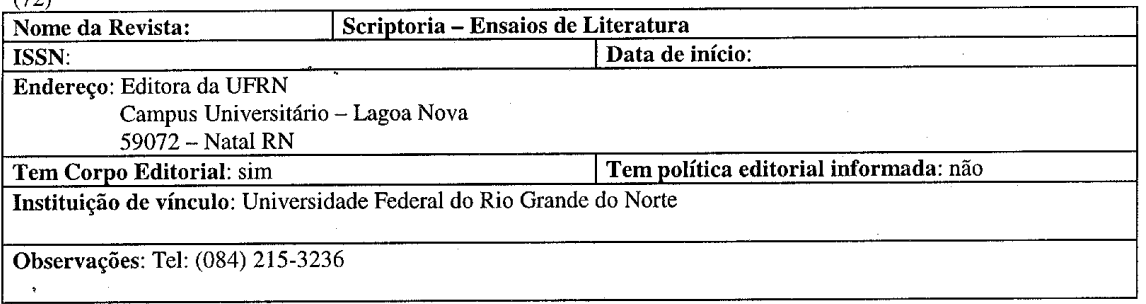

\begin{tabular}{l}
$(73)$ \\
\begin{tabular}{|l|l|}
\hline Nome da Revista: & Terceira Margem \\
\hline ISSN: & Data de início: 1993 \\
\hline $\begin{array}{l}\text { Endereço: Faculdade de Letras - Pós-Graduação } \\
\text { Universidade Federal do Rio de Janeiro } \\
\text { Cidade Universitária - Ilha do Fundão } \\
\text { 21491-000 Rio de Janeiro RJ }\end{array}$ \\
\hline Tem Corpo Editorial: sim & Tem política editorial informada: não \\
\hline Instituição de vínculo: Faculdade de Letras - UFRJ \\
\hline Observações: Tel: (021) 590-0212 R. 248
\end{tabular} \\
\hline
\end{tabular}

(74)

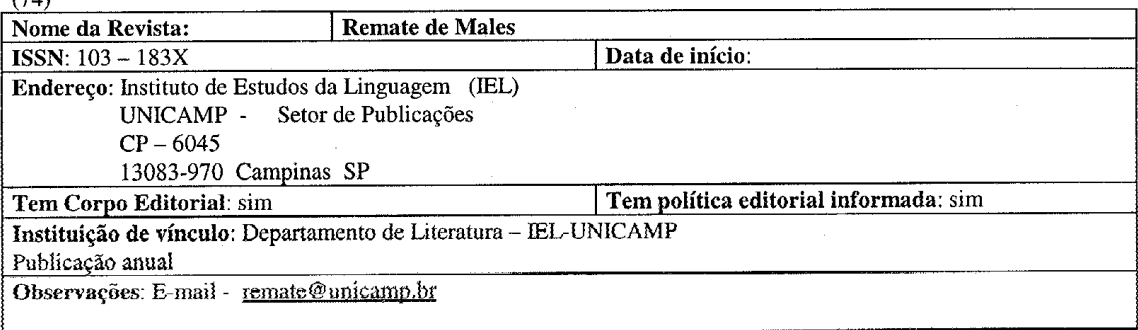


(75)

\begin{tabular}{|l|l|}
\hline Nome da Revista: & Vivência \\
\hline ISSN: $0104-3069$ & Data de início: 1983 \\
\hline $\begin{array}{l}\text { Endereço: Editora da Universidade Federal do Rio Grande do Norte } \\
\text { Campus Universitário - Lagoa Nova } \\
59072-970 \text { Natal RN }\end{array}$ \\
\begin{tabular}{l} 
Tem Corpo Editorial: sim \\
\hline Instituição de vínculo: Centro de Ciências Humanas, Letras e Artes \\
\hline
\end{tabular} \\
\hline
\end{tabular}

(76)

\begin{tabular}{|c|c|}
\hline Nome da Revista: & Línguas/ Instrumentos Lingüísticos \\
\hline ISSN: & \begin{tabular}{l|l} 
& Data de início:
\end{tabular} \\
\hline \multicolumn{2}{|c|}{$\begin{array}{l}\text { Endereço: Departamento de Linguística UNICAMP } \\
\text { C.P. } 6045\end{array}$} \\
\hline Tem Corpo Editorial: sim & Tem política editorial informada: sim \\
\hline \multicolumn{2}{|l|}{ Instituição de vínculo: } \\
\hline $\begin{array}{r}\text { Observações: Tel: } \\
\text { E-mail: }\end{array}$ & \\
\hline
\end{tabular}

(77)

\begin{tabular}{|l|l|}
\hline Nome da Revista: & Corpo e Voz \\
\hline ISSN: & Data de início: \\
\hline Endereço: & Faculdade de Ciências e Letras - Pós-Graduação \\
UNESP \\
CP. 174 \\
14800-901 Araraquara SP \\
Tem Corpo Editorial: sim \\
\hline Instituição de vínculo: Programa de Pós-Graduação em Lingüística e Língua Portuguesa \\
\hline Observações: E-mail - pgling@ @clar.unesp.br \\
\hline
\end{tabular}

(78)

\begin{tabular}{|l|l|}
\hline Nome da Revista: & \multicolumn{2}{|c|}{ Ao Pé da Letra - Revista dos alunos de Graduação em Letras } \\
\hline ISSN: & Data de início: 1999 \\
\hline Endereço: & $\begin{array}{l}\text { Departamento de Letras } \\
\text { Centro de Artes e Comunicação } \\
\text { Universidade Federal de Pernambuco } \\
\text { 50670-901 Recife PE }\end{array}$ \\
\hline Tem Corpo Editorial: sim & Tem política editorial informada: sim \\
\hline Instituição de vínculo: Departamento de Letras da UFPE \\
\hline $\begin{array}{l}\text { Observações: Revista com publicações de trabalhos exclusivamente de alunos de Graduação em Letras e Lingüística. } \\
\text { E-mail: dletras@ @npd.ufpe.br }\end{array}$ \\
\hline
\end{tabular}

(79)

\begin{tabular}{|l|l|}
\hline Nome da Revista: & Revista do GELNE: Grupo de Estudos Lingüísticos do Nordeste \\
\hline ISSN:1517-7874 & Data de início: 1999 \\
\hline Endereço: Centro de Hưmanidades & \\
Universidade Federala do Ceará & \\
Av. da Universidade 2683 & \\
Benfica & \\
$60020-180$ Fortaleza CE & Tem política editorial informada: sim \\
\hline Tem Corpo Editorial: sim & \\
\hline Instituiçẫo de vínculo: GELNE - Grupo de Estudos Lingǘsticos do Nordeste \\
\hline
\end{tabular}


(80)

\begin{tabular}{|l|l|}
\hline Nome da Revista: & Hispanista \\
\hline ISSN: & Data de início: \\
\hline Endereço eletrônico: $\frac{\text { http://www.hispanista.com.br }}{\text { Site situado na Universidade Federal Fluminense de Niterói }}$ \\
\hline Tem Corpo Editorial: & Tem política editorial informada: \\
\hline Instituição de vínculo: Revista Eletrônica dos hispanistas do Brasil \\
\hline Observações: Edição virtual \\
\hline
\end{tabular}

(81)

\begin{tabular}{|l|l|}
\hline Nome da Revista: & \multicolumn{1}{|l|}{ Revista Brasil de Literatura } \\
\hline ISSN: & \multicolumn{1}{|c|}{ Data de início: } \\
\hline Endereço eletrônico: http://members.tripod.com/ lfilipe/ \\
Site situado na Universidade Federal Fluminense de Niterói \\
\hline Tem Corpo Editorial: & Tem política editorial informada: \\
\hline Instituição de vínculo: Uiversidade Federal Fluminense \\
\hline Obsêtrvações: Revista eletrônica - Edição virtual
\end{tabular}

(82)

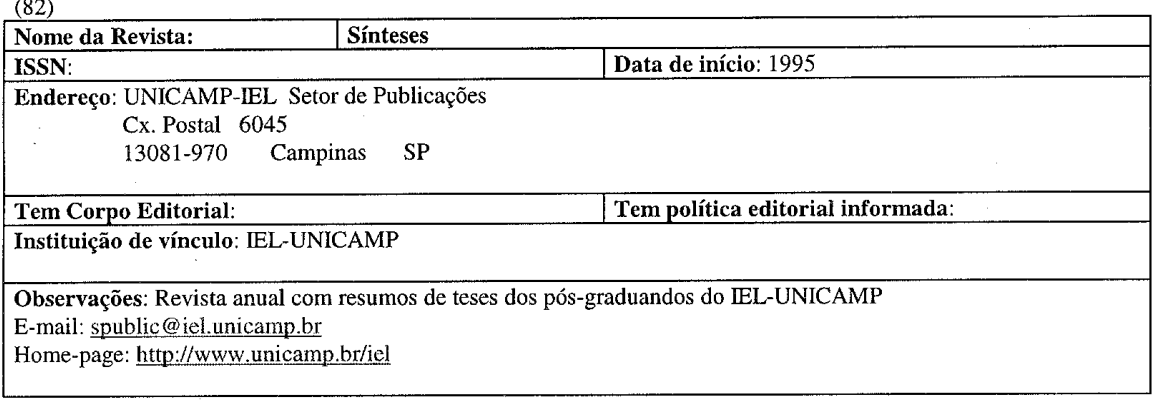

(83)

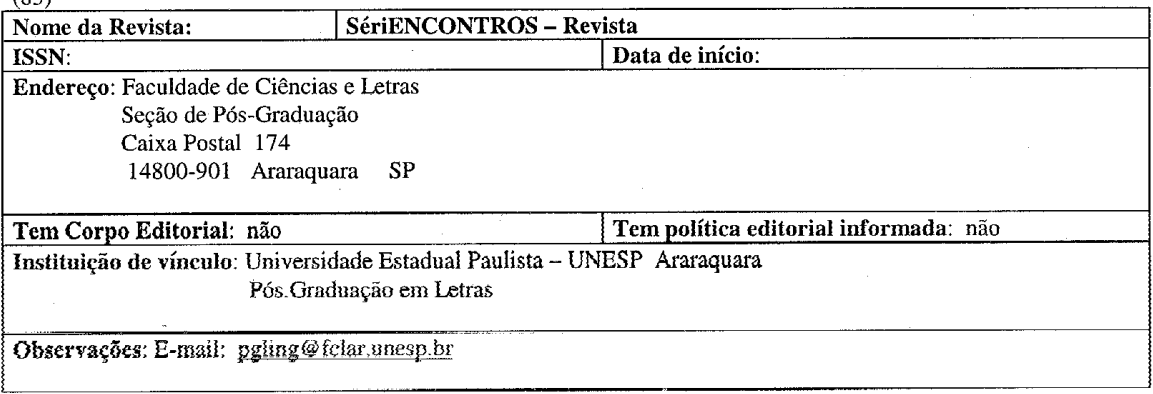


(84)

\begin{tabular}{|c|c|}
\hline Nome da Revista: & - Revista da Área de Língua e Literatura Inglesa e Norte-Americana \\
\hline ISSN: $1415-6253$ & Data de início: 1994 \\
\hline \multicolumn{2}{|c|}{$\begin{array}{l}\text { Endereço: Departamento de Letras Modernas - Área de Inlgês } \\
\text { Av. Prof. Luciano Gualberto, } 403 \\
\text { Cidade Universitária - USP } \\
\text { 05508-900 São Paulo SP }\end{array}$} \\
\hline Tem Corpo Editorial: sim & Tem política editorial informada: $\operatorname{sim}$ \\
\hline \multicolumn{2}{|c|}{ Instituição de vínculo: Departamento de Letras Modernas - Área de Inglês - USP } \\
\hline $\begin{array}{l}\text { Observações: Publicação anual } \\
\text { fone: (011) 210-2325 } \\
\text { E-mail: } \underline{\text { dml@edu.usp.br }}\end{array}$ & fax: (011) 818-5041 \\
\hline
\end{tabular}

(85)

\begin{tabular}{|c|c|}
\hline Nome da Revista: & \\
\hline ISSN: $1516-4586$ & Data de início: 1997 \\
\hline \multicolumn{2}{|c|}{$\begin{array}{l}\text { Endereço: Departamento de Letras Clássicas e Modernas } \\
\text { Faculdade de Filosofgia Letras e Ciências Humanas - USO } \\
\text { Av. Prof. Luciano Gualberto, } 403 \quad 2^{\circ} \text { andar, sala } 4 \\
\text { Cidade Universitária - USP } \\
\text { 05508-900 São Paulo SP }\end{array}$} \\
\hline Tem Corpo Editorial: sim & Tem política editorial informada: sim \\
\hline \multicolumn{2}{|c|}{ Instituição de vínculo: Departamento de Letras Clássicas e Modernas } \\
\hline $\begin{aligned} \text { Observações: Tel: (011) 818-4294 } & \\
& \text { E-mail: } \underline{\text { di@edu.usp.br }}\end{aligned}$ & \\
\hline
\end{tabular}

(86)

\begin{tabular}{|l|l|}
\hline Nome da Revista: & Cadernos do Centro de Línguas \\
\hline ISSN: $1415-3653$ & Data de início: 1997 \\
\hline Endereço: Centro de Línguas - FFCHL \\
Cidade Universitária - USP \\
Av. Prof. Luciano Gualberto, 403 \\
05508-900 São Paulo SP \\
\hline Tem Corpo Editorial: sim & Tem política editorial informada: sim \\
\hline Instituição de vínculo: Centro de Línguas da USP \\
\hline $\begin{array}{l}\text { Observações: tel: (011) 818-4589 } \\
\text { E-mail: clinguas@edu.usp.br }\end{array}$ \\
\end{tabular}

(87)

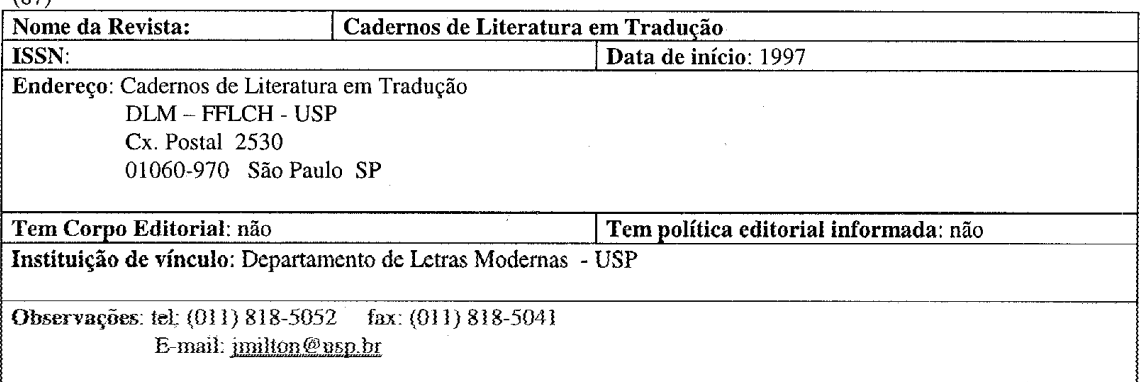


(88)

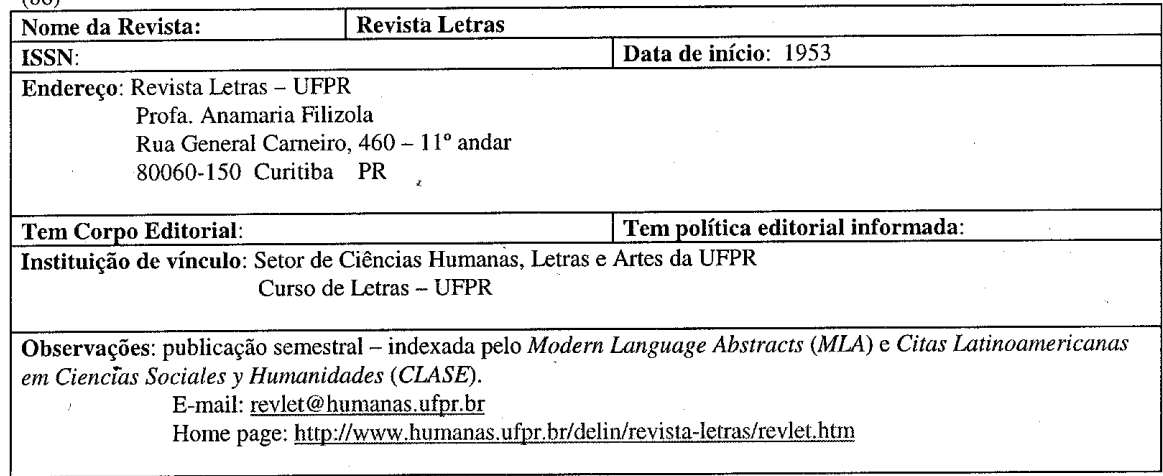

(89)

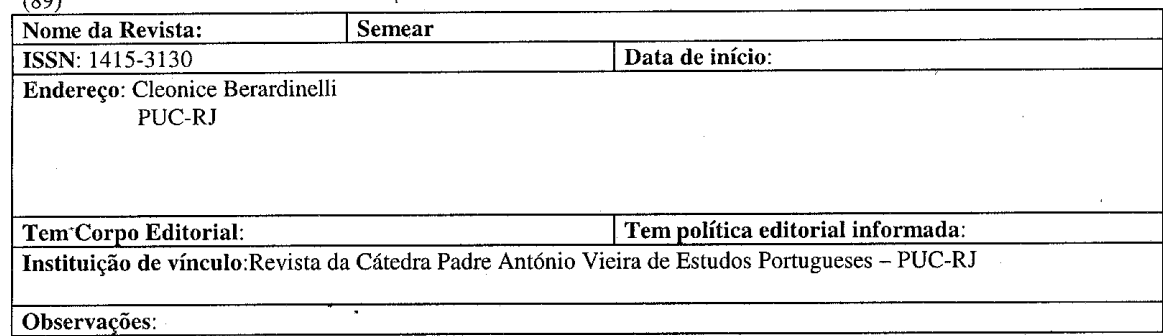

(90)

\begin{tabular}{|c|c|}
\hline Nome da Revista: & Via Atlântica \\
\hline ISSN: $1516-5159$ & Data de início: 1997 \\
\hline \multicolumn{2}{|c|}{$\begin{array}{l}\text { Endereço: Centro de Estudos Portugueses } \\
\text { Área de estudos Comparados de Literaturas de Língua Porguguesa } \\
\text { Faculdade de Filosofia e Ciências Humanas - USP } \\
\text { Av. prof. Luciano Gualberto } 403 \\
\text { 05508-900 São Paulo SP }\end{array}$} \\
\hline Tem Corpo Editorial: sim & Tem política editorial informada: sim \\
\hline \multicolumn{2}{|c|}{$\begin{array}{l}\text { Instituição de vínculo: : Centro de Estudos Portugueses / Área de estudos Comparados de Literaturas de Língua } \\
\text { Porguguesa }\end{array}$} \\
\hline
\end{tabular}

(91)

\begin{tabular}{|l|l|}
\hline Nome da Revista: & Revista da ABRAPLIP \\
\hline ISSN: & Data de início: 1999 \\
\hline Endereço: Centro de Estudos Portugueses & \\
FALE-UFMG & \\
Av. Antônio Carlos, 6627, Sala 3031 & \\
$31270-901 \quad$ Belo Horizonte MG & \\
\hline Tem Corpo Editorial: sim & Tem política editorial informada: sim \\
\hline Instituição de vínculo: Associação Brasileira de Professores de Literatura Portuguesa (ABRAPLIP) \\
\hline Observações: Tel: (031) 499-5134 \\
E-mail: cesp@ @letras.ufmg.br
\end{tabular}


(92)

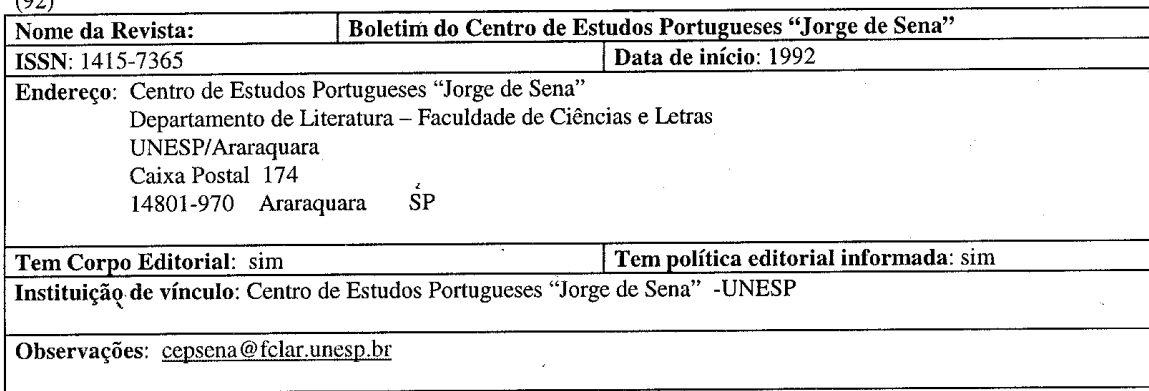

(93)

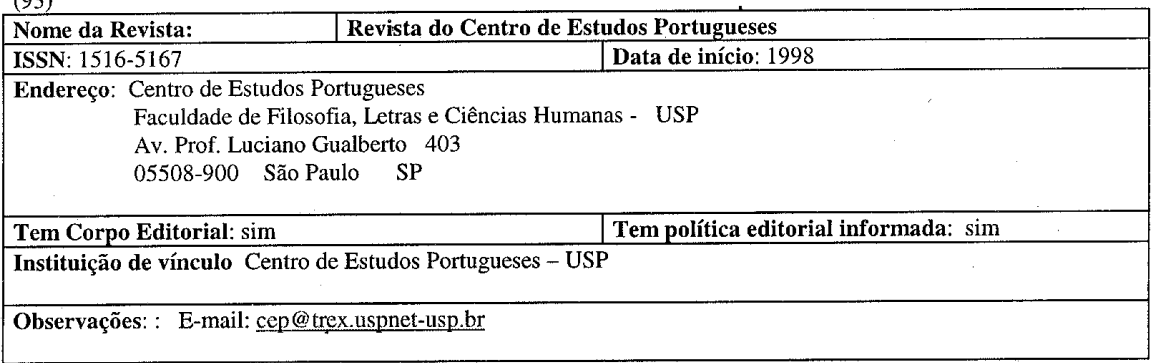

(94)

\begin{tabular}{|c|c|}
\hline Revista Confluência & \\
\hline ISSN: $1415-7403$ & Data de início: $1^{\circ}$ semestre de 1991 \\
\hline \multicolumn{2}{|c|}{$\begin{array}{l}\text { Endereço: Instituto de Língua Portuguesa do Liceu Literário Português do Rio } \\
\text { Rua Senador Dantas , } 118\end{array}$} \\
\hline Tem Corpo Editorial: Sim & Tem política editorial informada: Sim \\
\hline \multicolumn{2}{|c|}{ Instituição de vínculo: Instituto de Língua Portuguesa do Liceu Literário Português / RJ } \\
\hline $\begin{array}{l}\text { Observaçôes: Publicação semestral } \\
\text { Tel. (21) } 220-5495 / 2205445 \\
\text { Fax: (21) } 533-3044\end{array}$ & 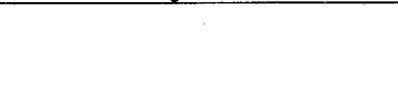 \\
\hline
\end{tabular}

(95)

\begin{tabular}{|c|c|}
\hline Nome da Revista: & Cadernos de Letras da UFF \\
\hline ISSN: & Data de início: \\
\hline $\begin{array}{l}\text { Endereço: Av. Visconde do Rio } \\
\text { Campus do Gragoatá } \\
\text { Bloco C - Sala 501 } \\
24220-200 \text { Niterói }\end{array}$ & $\begin{array}{l}\text { Branco s/n } \\
\text { - UFF } \\
\text { RJ }\end{array}$ \\
\hline Tem Corpo Editorial: & Tem política editorial informada: \\
\hline Instituiçân de víneulo: Instituts & de Letras da UFF \\
\hline
\end{tabular}


(96)

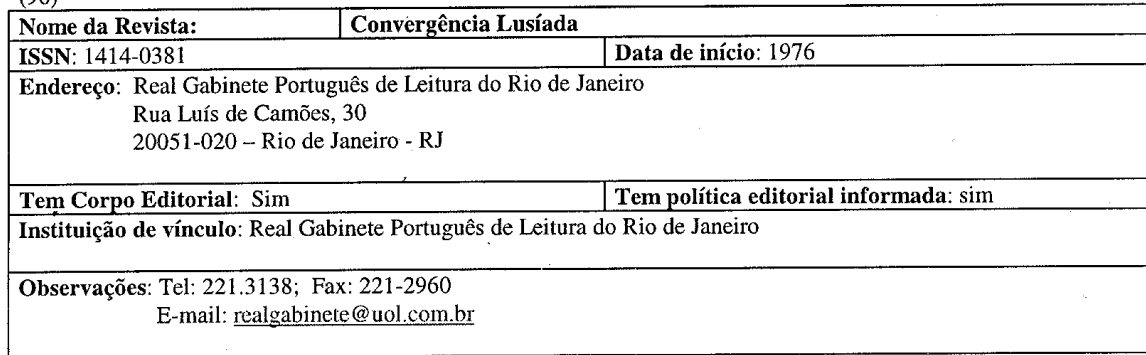

(97)

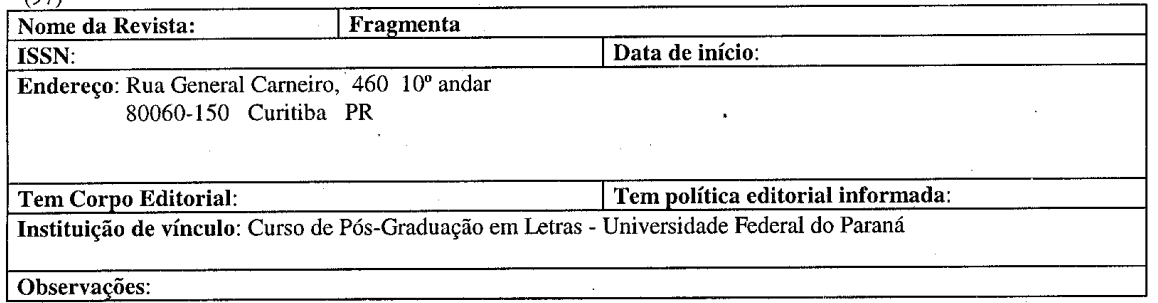

(98)

\begin{tabular}{|l|l|}
\hline Nome da Revista: & \multicolumn{2}{|l|}{ Ipotesi - Revista de Estudos Literários } \\
\hline ISSN: $1415-2525$ & Data de início: \\
\hline $\begin{array}{c}\text { Endereço: Departamento de Letras } \\
\text { Universidade Federal de Juiz de Fora - UFJF }\end{array}$ \\
\hline Tem Corpo Editorial: \\
\hline Instituição de vínculo: Departamento de Letras UFJF & Tem política editorial informada: \\
\hline Observações: E-mail: pgletras@artnetcom.br
\end{tabular}

(99)

\begin{tabular}{|c|c|}
\hline Nome da Revista: & Quinto Império - Revista de Cultura e Literatura de Língua Portuguesa \\
\hline ISSN: $1415-1758$ & \begin{tabular}{l|l|} 
& Data de início: 1986 \\
\end{tabular} \\
\hline $\begin{array}{c}\text { Endereço: Gabinete Português de } \\
\text { Praça da Piedade s/n } \\
40070-010 \text { Salvador }\end{array}$ & $\begin{array}{l}\text { Leitura da Bahia } \\
\text { BA }\end{array}$ \\
\hline Tem Corpo Editorial: & Tem política editorial informada: \\
\hline Instituição de vínculo: Gabinete & Português de Leitura da Bahia \\
\hline
\end{tabular}

(100)

\begin{tabular}{|c|c|}
\hline Nome da Revista: & Encontro - Revista do Gabinete Português de Leitura \\
\hline ISSN: & \begin{tabular}{|l|l|} 
& Data de início: 1986 \\
\end{tabular} \\
\hline $\begin{array}{c}\text { Endereço: Gabinete Português d } \\
\text { Rua do Imperador, } 2 \\
50010-010 \text { Recife }\end{array}$ & $\begin{array}{l}\text { Leitura } \\
0 \\
\text { PE }\end{array}$ \\
\hline Tem Corpo Editorin\}: sim & Tem politica editorial informada; năo \\
\hline 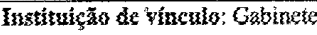 & Portugugés de Keikara \\
\hline
\end{tabular}


(101)

\begin{tabular}{|l|l|}
\hline Nome da Revista: & \multicolumn{1}{|c|}{ Boletim do Centro de Estudos Portugueses da UFPI } \\
\hline ISSN: & Data de início: 1999 \\
\hline $\begin{array}{l}\text { Endereço: Centro de Estudos Portugueses } \\
\text { Universidade Federal do Piauí } \\
\text { Teresina PI }\end{array}$ \\
\hline Tem Corpo Editorial: \\
\hline Instituição de vínculo: \\
\hline Observações:
\end{tabular}

(102)

\begin{tabular}{|c|c|}
\hline Cadernos do IL & \\
\hline ISSN: $0104-1886$ & Data de início: 1989 \\
\hline $\begin{array}{l}\text { Endereço: Universidade Federal do Rio Grande do Sul } \\
\text { Instituto de Letras } \\
\text { Av. Bento Gonçalves, } 9500 \\
91540-000 \text { - Porto Alegre - RS }\end{array}$ & $\overline{.}$ \\
\hline Tem Corpo Editorial: Sim & Tem política editorial informada: sim \\
\hline \multicolumn{2}{|l|}{ Instituição de vínculo: Instituto de Letras da UFRGS } \\
\hline $\begin{array}{l}\text { Observações: E-mail: iletras @ vortex.ufrgs.br } \\
\text { Home Page: http://www.ufrgs.br/iletras } \\
\text { Tel: (0xx51) } 3166689 \quad \text { Fax: (0xx51) } 3\end{array}$ & \\
\hline
\end{tabular}

(103)

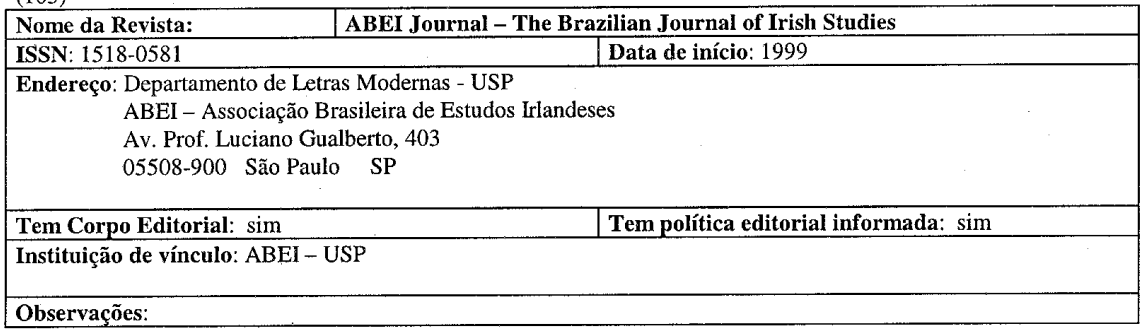

(104)

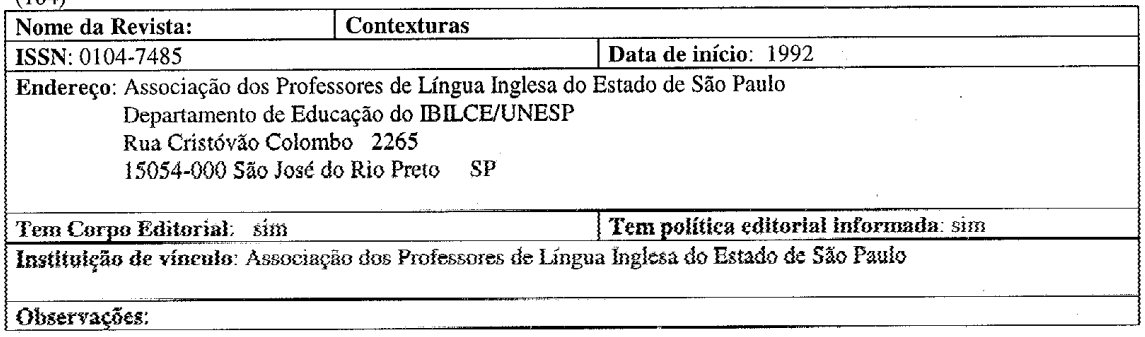


(105)

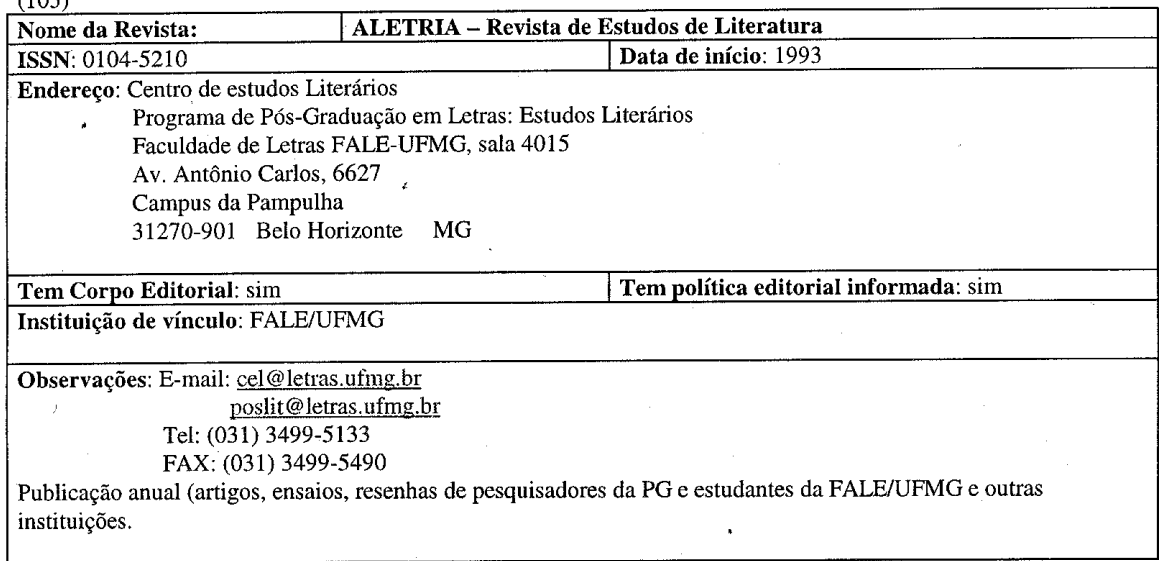

(106)

\begin{tabular}{|l|l|}
\hline Nome da Revista: & \multicolumn{1}{|l|}{ Arte \& Linguagem - Língua e Literatura na Educação } \\
\hline ISSN: & Data de início: \\
\hline $\begin{array}{l}\text { Endereço: Pontifícia Universidade Católica de São Paulo } \\
\text { Departamento de Linguíítica } \\
\text { R. Monte Alegre, 984, } \\
\text { 05014-001 São Paulo SP }\end{array}$ \\
\hline Tem Corpo Editorial: sim \\
\hline Instituição de vínculo: PUC-São Paulo \\
\hline Observações: Edição EDUC-Cortez (São Paulo)
\end{tabular}

\begin{tabular}{|l|l|}
\hline Nome da Revista: & \multicolumn{2}{|l|}{ Lácio-Revista de Letras do Unicentro Newton Paiva } \\
\hline ISSN: & Data de início: 1999 \\
\hline $\begin{array}{l}\text { Endereço: } \\
\text { Rua Goitacases, } 1762 \\
\text { Barro Preto } \\
\text { 30190-052 Belo Horizonte MG }\end{array}$ \\
\hline Tem Corpo Editorial: sim & Tem política editorial informada:sim \\
\hline Instituição de vínculo: CENTRO UNIVERSITÁRIO NEWTON PAIVA \\
\hline Observações:
\end{tabular}

(108)

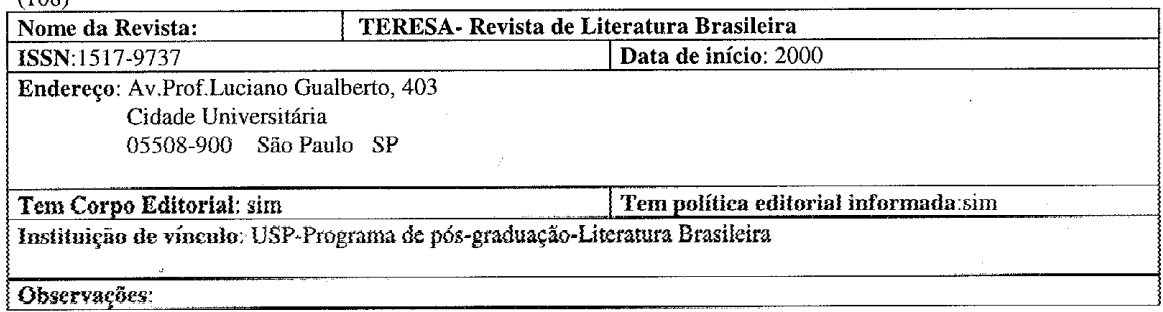


(109)

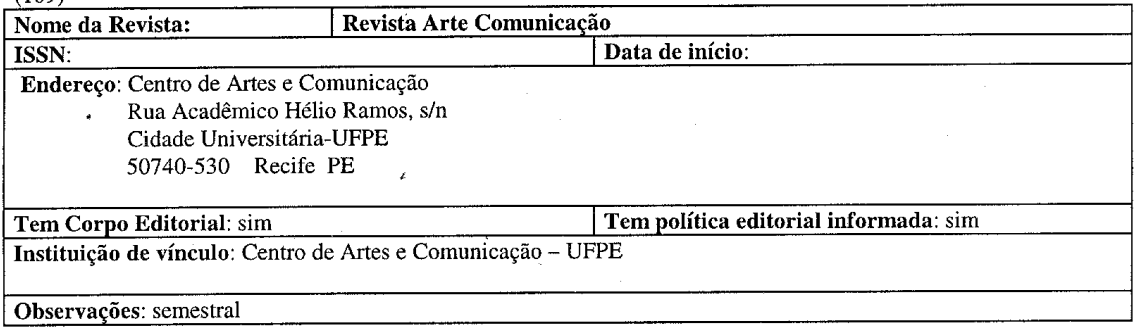

(110)

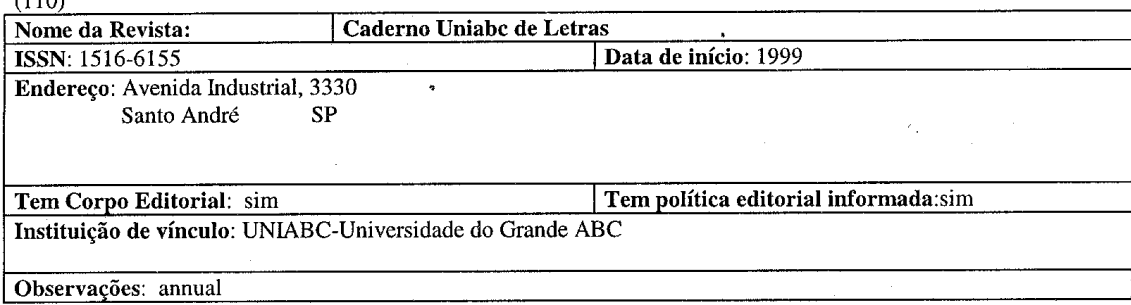

(111)

\begin{tabular}{|l|l|}
\hline Nome da Revista: & Estudos Japoneses \\
\hline ISSN: $1413-8298$ & Data de início: 1979 \\
\hline Endereço: Centro de Estudos Japoneses da Universidade São Paulo \\
Av. Prof. Lineu Prestes, 159 \\
Cidade Universitária USP \\
05508-900 São Paulo SP \\
\hline $\begin{array}{l}\text { Tem Corpo Editorial: sim } \\
\text { daUniversidade de São Paulo }\end{array}$ \\
\hline $\begin{array}{l}\text { Observações: publicação anual } \\
\text { E-mail: cejap@edu.usp.br }\end{array}$ \\
\hline
\end{tabular}

(112)

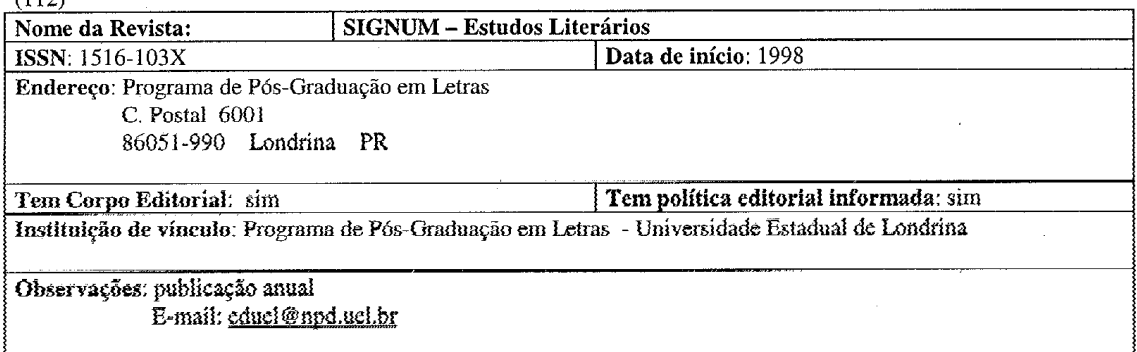


(113)

\begin{tabular}{|c|c|}
\hline Nome da Revista: & \\
\hline ISSN: 0102-6968 & Data de início: 1980 \\
\hline $\begin{array}{l}\text { Endereço: Universidade Estadual de Londrina } \\
\text { Centro de Letras e Ciências Humanas } \\
\text { C. Postal } 6001 \\
86051-990 \quad \text { Londrina PR }\end{array}$ & - \\
\hline Tem Corpo Editorial: sim & Tem política editorial informada: sim \\
\hline \multicolumn{2}{|c|}{ Instituição de vínculo: Centro de Letras e Ciências Humanas - Universidade Estadual de Londrina } \\
\hline $\begin{array}{l}\text { Observações: publicação semestral } \\
\text { E-mail: disque-gramatical@uel.br }\end{array}$ & \\
\hline
\end{tabular}

(114)

\begin{tabular}{|c|c|c|}
\hline Nome da Revista: & Graphos & \\
\hline \multicolumn{2}{|l|}{ ISSN: $1516-1536$} & Data de início: 1997 \\
\hline \multicolumn{3}{|c|}{$\begin{array}{l}\text { Endereço: Programa de Pós-Graduação em Letras } \\
\text { Universidade Federal da Paraíba } \\
\text { Centro de Ciências Humanas, Letras e Artes } \\
\text { Cidade Universitária } \\
\text { 58.051-900 - João Pessoa - PB }\end{array}$} \\
\hline \multicolumn{2}{|c|}{ Tem corpo editorial: Sim } & Tem política editorial informada: Sim \\
\hline \multicolumn{3}{|c|}{ Instituição de vínculo: Universidade Federal da Paraíba } \\
\hline \multicolumn{3}{|c|}{$\begin{array}{l}\text { Observações: Semestral } \\
\qquad \begin{array}{l}\text { Fone: (83) 216-7289/ (83) 216-7335 (fax) } \\
\text { E-mail: posletras@ @cchla.ufpb.br }\end{array}\end{array}$} \\
\hline
\end{tabular}

(115)

\begin{tabular}{|l|l|}
\hline Nome da Revista: & \multicolumn{1}{|c|}{ Cadernos de Língua e Literatura Hebraica } \\
\hline ISSN: $1415-7977$ & Data de início: 1998 \\
\hline Endereço: Departamento de Literaturas Orientais & \\
Faculdade de Filosofia Línguas Ciêncais e Letras - USP \\
Av. Prof. Luciano Gualberto, 403 \\
C. Postal 8105 \\
05508-900 São Paulo SP \\
Tem Corpo Editorial: sim & Tem política editorial informada: sim \\
\hline Instituição de vínculo: FFLCH-USP - Área de Pós-Graduação em Língua Hebraica, Literatura e Cultura Judaicas \\
\hline Observações: anual \\
E-mail: pubflch@edu.usp.br \\
H-Page: http://www.usp.br/fflch/fflch/html
\end{tabular}

(116)

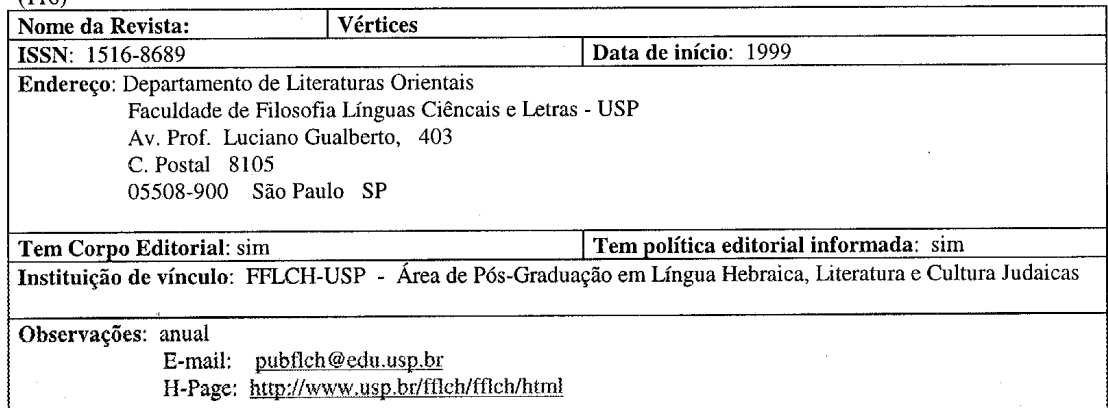


(117)

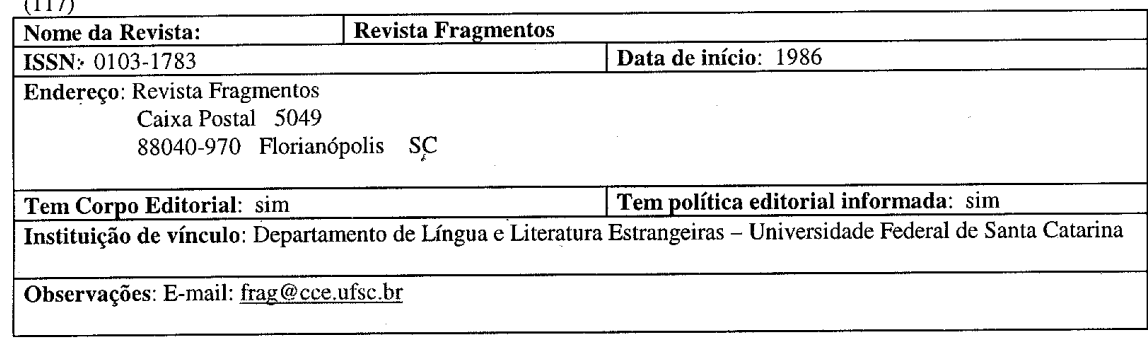

(118)

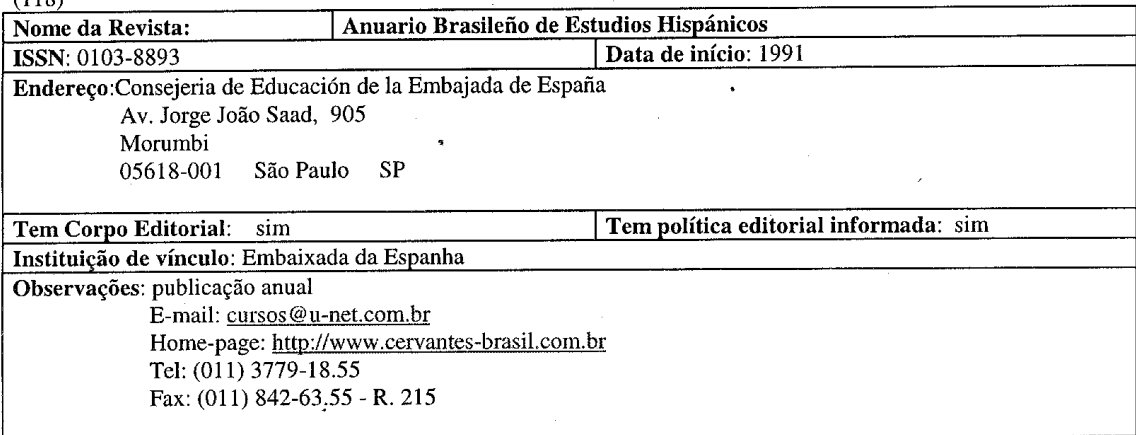

(119)

\begin{tabular}{|l|l|}
\hline Nome da Revista: & \multicolumn{2}{|l|}{ Revista de la APEESP } & \\
\hline ISSN: & Data de início: 1991 \\
\hline Endereço:Revista de La APEESP \\
Av. Prof. Luciano Gualberto, 403 Prédio de Letras \\
FFLCH/DLM/USP \\
C. Postal 2530 \\
01060-970 São Paulo SP \\
\hline Tem Corpo Editorial: não \\
\hline Instituição de vínculo: USP \\
\hline Observações: publicação bienal \\
E-mail: 1 rogerio@ originet.com.br \\
Fax: (011) 3871-2709
\end{tabular}

(120)

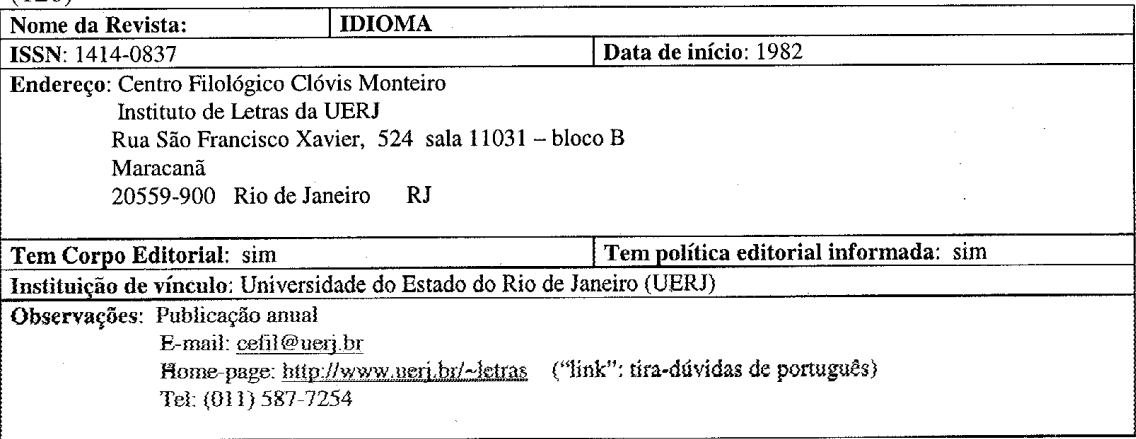


(121)

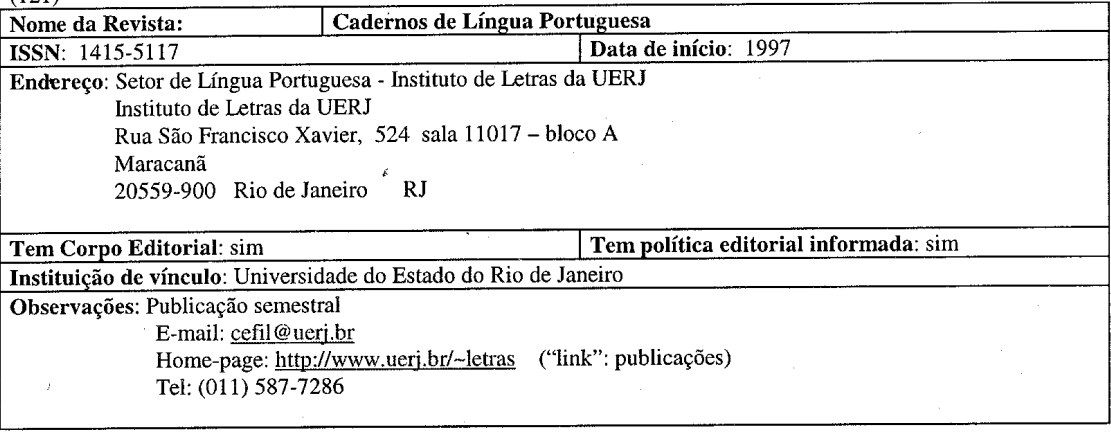

(122)

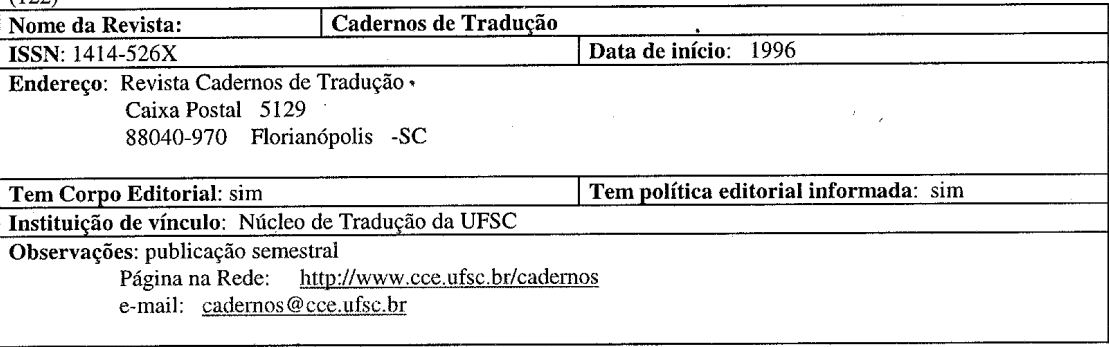

(123)

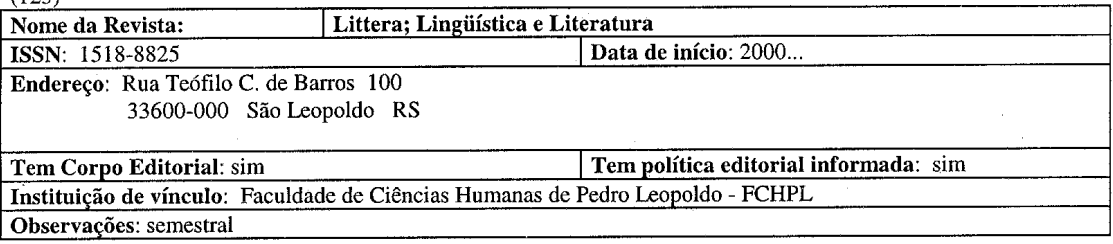

(124)

\begin{tabular}{|l|l|}
\hline Nome da Revista: & Coleção Ensaios \\
\hline ISSN: 1519-0218 & Data de início: $1998-\ldots$ \\
\hline Endereço: Universidade Federal de Santa Maria \\
Prédio do centro de Educação, Letras e Biologia \\
Mestrado em Letras - Sala 3222 - Bloco A2 \\
97105-900 - Santa Maria - RS \\
\hline Tem Corpo Editorial: sim & Tem política editorial informada: não \\
\hline Instituição de vínculo: & \\
\hline Observações: Anual \\
E-mail: mletras@ cal.ufsm.br \\
Assinaturas: http://www,ufsm.br/mletras \\
Fone/ fax: (055) 2208359
\end{tabular}

(125)

\begin{tabular}{|c|c|}
\hline Nome da revista: & \\
\hline ISSN : $1414-0837$ & Data de início: 1971 \\
\hline $\begin{array}{l}\text { Endereço: Centro Filológico Clóvis Monteiro } \\
\text { Instituto de Letras da UERJ } \\
\text { Universidade do Estado do Rio de Janeiro } \\
20000-000 \text { Rio de Janeiro RJ }\end{array}$ & \\
\hline Ten corpo editorial: sim & Tem política editorial informada: sim \\
\hline Instituiçä de vinculs: UER3 & \\
\hline Observaçōes: anual & \\
\hline
\end{tabular}


(126)

\begin{tabular}{|l|l|}
\hline Nome da revista: & Linguagem em (Dis)curso \\
\hline
\end{tabular}

\begin{tabular}{l|l}
\hline ISSN : $1518-7632$ & Data de início: 2000
\end{tabular}

Endereço: Curso de Mestrado em Ciências da Linguagem

Centro de Pós-Graduação de Tubarão

Av. Marcolino Martins Cabral, 39

88701-000 Tubarão SC

Tem corpo editorial: $\operatorname{sim}$

Tem política editorial informada: $\operatorname{sim}$

Instituição de vínculo: Universidade do Sul de Santa Catarina - UNISUL

Observações: semestral

http://visao.unisul.br/linguagem/Revista/index/html

(127)

\begin{tabular}{|l|l|}
\hline Nome da revista: & \multicolumn{2}{|l|}{ Open to Discussion } \\
\hline ISSN : 1516-7682 & Data de início: 1991 \\
\hline Endereço: Departamento de Letras Anglo-germânicas \\
Universidade do Estado do Rio de janeiro \\
Rua São Francisco Xavier $524 / 11.002$ bl. A \\
20550-013 Rio de Janeiro RJ \\
\hline Tem corpo editorial: sion & Tem política editorial informada: sim \\
\hline Instituição de vínculo: Universidade do Estado do Rio de janeiro -UERJ \\
\hline $\begin{array}{l}\text { Observações: Tel-fax: (021) 587.71.49 } \\
\text { www2.uerj.br/ letras }\end{array}$ \\
\hline
\end{tabular}

(128)

\begin{tabular}{|c|c|}
\hline Nome da revista: & Letr@Viv@ \\
\hline ISSN : $1517-3100$ & Data de início: 1999 \\
\hline $\begin{array}{r}\text { Endereço: Cidade Universi } \\
\text { Centro de Ciênci } \\
\text { Departamento d } \\
\text { João Pessoa }\end{array}$ & $\begin{array}{l}\text { Campus I } \\
\text { manas Letras e Artes } \\
\text { s Modernas. }\end{array}$ \\
\hline Tem corpo editorial: sim & \begin{tabular}{l|l|} 
& Tem política editorial informada: sim \\
\end{tabular} \\
\hline
\end{tabular}

\begin{tabular}{|l|l|}
\hline Nome da revista: & \multicolumn{2}{|l|}{} \\
\hline ISSN : & Data de início: \\
\hline Endereço: & Tem política editorial informada \\
\hline Tem corpo editorial: & \\
\hline Instituição de vínculo: & \\
\hline Observaçôes: & \\
\hline
\end{tabular}

